\title{
EL ARTISTA EN EL PAISAJE COMO FIGURA DEL «OTIUM»
}

Data recepción: 2012/02/03

Data aceptación: 2012/07/26

Contacto autor: federico.lopez.silvestre@usc.es
Federico L. Silvestre

Universidade de Santiago de Compostela

\section{RESUMEN}

Un cuadro de Jan Both, Paisaje italiano con dibujante del Rijksmuseum de Amsterdam, sirve como excusa para plantear dos problemas: por un lado, el de la representación del artista en el paisaje en el siglo XVII; por otro, el del sentido de este tipo de representación en el caso específico de los paisajistas italianizantes holandeses. Lógicamente, si en las páginas que siguen el investigador se detiene en algunas obras apenas recordadas, es porque las considera claves para resolver estas cuestiones y para recordar la evolución de cierto paisajismo intradiegético hoy casi olvidado. Quizás otros personajillos [staffage] sólo jugaron un papel secundario en el contenido de muchos paisajes rurales o urbanos. Sin embargo, por pequeño que resulte, la representación del propio artista fue siempre un tema de diferente calado.

Palabras clave: artista en el paisaje, «tekenaar», Jan Both, «staffage», Claudio de Lorena

\begin{abstract}
Jan Both's Italian Landscape with Draughtsman (Rijksmuseum, Amsterdam) provides the basis for the posing of two problems: namely the representation of the artist in 17th-century landscapes, and the meaning behind this type of representation in the specific case of Dutch Italianate landscape painters. If, in the pages that follow, the researcher has chosen to devote his attention to some scarcely remembered works, it is because he believes them to be crucial in resolving these questions and in recalling the development of an intradiegetic landscape art that is virtually forgotten today. While it is perhaps the case that staffage played only a secondary role in the content of many rural and urban landscapes, the representation of the artist themselves has always been an altogether more substantial topic of debate, no matter how small they may appear.
\end{abstract}

Keywords: artist in the landscape, «tekenaar», Jan Both, staffage, Claude Lorrain

\section{La profesión de «tekenaar»}

Puede parecer que en el seiscientos los artistas de los Países Bajos usaron el tema ya inventado del landschap met tekenaar -en holandés, «paisaje con dibujante»- sin más motivo que el de establecer la envergadura de lo que presentaban, realzar su monumentalidad y atraer la atención del espectador para orientar el recorrido de su mirada. Sin embargo, puesto que parte de la crítica especializada coincide en que «la cuestión de esas figurillas humanas y de animales pintadas en una escena [staffage] introduce el problema global de la relación entre el hombre y la naturaleza en la Holanda del siglo XVII tanto en pintura como en general», parece justificado volver a detenerse en un análisis pormenorizado del caso ${ }^{1}$. Como ya hemos hecho en otros lugares, el objetivo fundamental de estas páginas consiste en fijarse en una figura emblemática: la del artista en el paisaje².

A modo de hilo conductor, una obra clave: el Paisaje italiano con dibujante del Rijksmuseum de Amsterdam $^{3}$ (Fig. 1). Su autor, Jan Both (ca. 1618-1652), se forma en Utrecht y, a continuación, viaja a Roma para ver a su hermano hacia 1638, permaneciendo allí hasta $1641^{4}$. Cuando pinta este cuadro entre 1650 y 1652 lleva años de nuevo en su casa, en Holanda, donde des- 


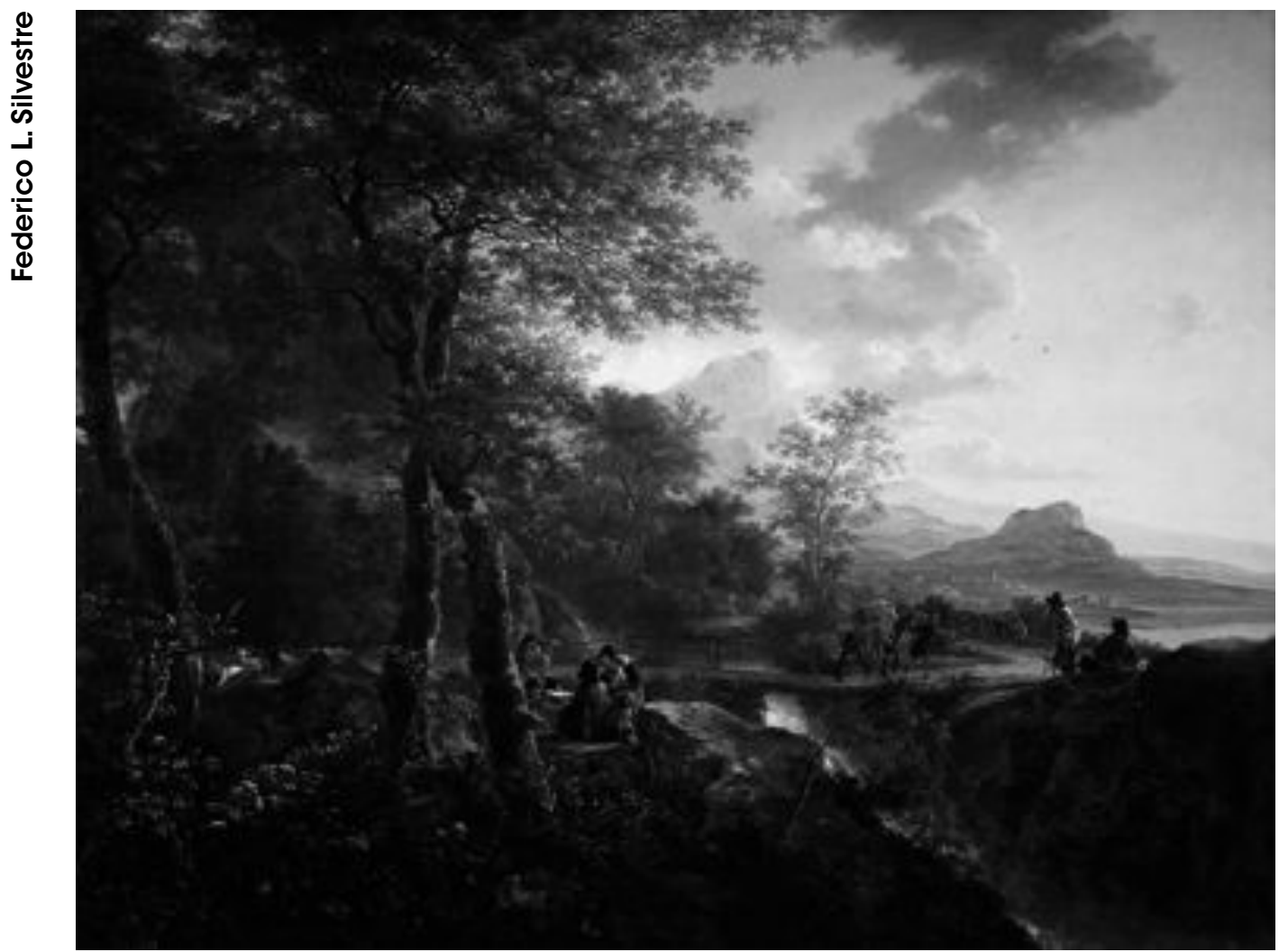

Fig. 1 Jan Both: Paisaje italiano con dibujante, ca. 1650, óleo sobre lienzo, 240 x 187 cm, Amsterdam, Rijksmuseum, inv. nr. SKC-109.

graciadamente muere joven. Con el tiempo, sus idealizantes cuadros caen en desgracia ${ }^{5}$. Pero, frente a ello, de él se ha dicho que fue el mejor pintor holandés de «escenas italianas» del XVII. Si a esto se añade su contrastado liderazgo ${ }^{6}$, no podrá extrañarle a nadie que aquí se presente su Paisaje italiano con dibujante -con su estudiada variedad de luces y nubes, con sus arbustos y árboles lujuriantes, con su charla de artistas, pastores y cabras, y con sus viajeros con mulascomo la mejor plasmación del tema del artista en el paisaje del siglo XVII ${ }^{7}$. Ahora bien, ¿por qué autorrepresentarse? ¿Se trata de algo anecdótico o importante? ¿Qué cambia en relación a los «artistas en el paisaje» que lo preceden? ¿De dónde, su modelo? Y, ¿por qué esa insistencia en «Italia»?

Como se verá, en estas páginas planteo que nada es casual en el cuadro de Amster- dam. De Both apenas nos quedan datos. Sabemos que, probablemente, fue el mejor paisajista italianizante holandés del XVII, y nos consta que nadie estuvo a su nivel en el gran formato. Pero, de las doscientas obras que figuran en su catálogo, sólo ocho aparecen fechadas ${ }^{8}$. Por el contrario, se conservan muchas noticias sobre sus precedentes, su círculo romano y sus seguidores. Partiendo de las mismas, trataré de reconstruir el proceso de concepción de la obra, el origen de sus elementos, las técnicas utilizadas y el valor y sentido profundos que con ella nos ha legado.

Si, a mi juicio, merece tanta atención es porque, gracias a su calidad y a los motivos que incorpora, condensa en un lienzo la importancia en la época del tema del artista en el paisaje, la satisfacción en la vida, la plenitud de las sensaciones, la belleza como felicidad, los 
ideales dóricos y estables, en general, «la descripción de lo inmutable, lo que descansa en sí mismo» ${ }^{9}$.

Carel van Mander y el dibujo al natural en el siglo XVII. En primer lugar, llama la atención que Both parezca introducir, no un artista, sino varios -al menos, uno conversando con otros personajes-. La acumulación de figuras [staffage] responde a una variedad iconográfica que termina de cuajar a lo largo del siglo XVII. No obstante, conviene empezar insistiendo en que no resulta extraño que sea un holandés el encargado de introducir ese cambio. Ya en otros cuadros de su propia mano comprobamos que Both se había acostumbrado a multiplicar los jinetes, pastores, viajeros y dibujantes. Se ha señalado que el holandés usó esas figuras «no sólo para dirigir [la mirada], sino también como contrapunto» ${ }^{10}$. Frente a otros personajes, esto resulta evidente en el caso de sus dibujantes. En todo caso, en este tema, a la altura de 1650, los paisajistas holandeses contaban ya con una importante tradición avalándolos.

Para empezar, los paisajes holandeses sin figuras de ninguna clase en este periodo fueron «un fenómeno extremadamente raro»y, entre ellos, «un considerable número [...] incluyó dibujantes y unos pocos dibujos parecen representar excursiones artísticas para hacer croquis» ${ }^{11}$. Esto es clave. Efectivamente, la presencia de esos dibujantes en los paisajes registra, en primer lugar, una práctica real de la época cada vez más extendida por los campos. Los precedentes flamencos de Brueghel, Hoefnagel, Valckenborch o Savery debieron jugar un papel importante ${ }^{12}$. Pero, ahora, en el seiscientos, la técnica de realizar croquis al aire libre pasa a ser defendida por casi todos los talleres y los críticos holandeses importantes.

En el libro de pintura más importante del nuevo siglo en los Países Bajos, el Schilderboeck [Libro de los pintores] de Carel van Mander (1604), descubrimos al menos dos lugares en los que se hace referencia de diferentes modos a la cuestión. Por un lado, en las Vidas de los más ilustres pintores de los Países Bajos y de Alemania Mander habla del valor de las figuras de los paisajes pintados por Pieter Brueghel el Viejo $y$, en general, de la importancia de las storyken o "pequeñas historias» ${ }^{13}$. Pero, por otro, en el tratado sobre El fundamento del noble arte de la pintura incluido al comienzo de la misma obra, Mander subraya el valor de los apuntes del natural con la ayuda de un largo poema del pintor Pieter Cornelisz Ketel titulado La canción del paisajista. Dice así:

Cuando la novia de Titono, Aurora, se levanta, despertaos, jóvenes pintores, y saltad de vuestras camas. Os debéis acostumbrar a salir temprano para que lleguéis a tiempo de ver el sol rompiendo a través de la neblina y revelando la belleza de la tierra. I Tomad el carboncillo y la tiza, la pluma, la tinta y el papel; dibujad lo que veis, todo lo que complazca al ojo. Prestad siempre atención a lo que os dicen vuestros ojos: notad, por ejemplo, cómo todo, incluso en lo más lejano se une en un punto central. I Cuando dibujéis algo que está cerca de vosotros, no os pongáis demasiado cerca, que eso estropea el efecto. si os ponéis un poco distantes, el efecto de la escena para el ojo resultará más agradable. Sentaos en un bosque y mirad a vuestro alrededor. Notad cómo los objetos más lejanos son menos distintos que los que están cerca de vosotros: notad también cómo el primer plano se adelanta hacia vosotros y cuán precisas son las hojas de los árboles más próximos comparadas con los tonos más sutiles de las que están más lejos. De este modo aprenderéis qué es lo que debe pintarse en colores intensos y qué en colores más suaves. I Pintad todo lo que hay en el jardín plancentero de Pan, ya sean bosques, montañas o cavernas. Dibujad todo lo que atraiga vuestro ojo, pero con entendimiento. Dibujad poblaciones, castillos y granjas; cabañas de campesinos, caminos y puentes. No paséis nada por alto: dibujad ríos, corrientes y cascadas. I Volved a la ciudad cuando las hojas de los árboles que os dieron sombra ya no os sirvan. Los paisajes que habéis visto $y$ registrado en vuestro cuaderno debéis pintarlos en casa, y darles vida con colores que hayáis molido vosotros mismos. La Fama os traerá trabajo y alto nombre, y muchos amantes del arte os darán dinero por vuestras pinturas ${ }^{14}$. 
Tras leer esto, parece obvio que los artistas en el paisaje que se multiplican en los cuadros y dibujos de las Provincias Unidas del Norte en el XVII son la simple constatación de que la nueva práctica plenairista que aconsejaba Van Mander fue seguida por muchos. Desde luego, la lista de dibujos y cuadros de paisajistas en paisajes que conservamos prueba el éxito de la fórmula.

Entre los artistas holandeses que representan el tema entre 1600 y 1650 destacan Jan Van de Velde, Allaert van Everdingen, Jan Lievens, Rembrandt -con su Boerderij en stallen, met een zittende tekenaar, de 1643-1647-, Visscher y Van der Haagen ${ }^{15}$. En todo caso, éstas son sólo las firmas más conocidas de una largísima lista en la que, cada uno a su manera, todos aportan algo al tema ${ }^{16}$.

Es en este repertorio considerable de dibujos, aguadas y grabados anteriores a 1650 donde cuaja el tópico de los dibujantes que luego encontramos en la obra de Both. En los mismos los pequeños tekenaars lo captan todo, desde ruinas de monumentos antiguos -como en el famoso autorretrato de Heemskerck-, hasta espacios rurales, campos abiertos, humildes cabañas, valles, bosques, montañas, cascadas, iglesias y marinas. Por otro lado, su disposición varía: los hay sentados -la mayoría-, los hay en pie, los encontramos escondidos en un rincón, los hay casi en primer plano o en lo alto...

Su presencia resulta fundamental desde el punto de vista compositivo y para hacerse cargo de la escala. En todo caso, comparando el lienzo de Both de hacia 1650 con los apuntes de los artistas comentados se perciben varias novedades. Por un lado, el protagonismo mucho mayor de un tema que pasa de ser anecdótico -sólo presente en dibujos y grabados ${ }^{17}$ - a central -protagonizando un gran óleo y el título del trabajo-; por otro, su carácter meridional..., pues el cuadro de Both se conoce como «Paisaje italiano con dibujante».

El taller de los Brill y el dibujante en el paisaje. Efectivamente, contrastando las obras penetradas por la experiencia italiana con las producidas sin salir de los Países Bajos, salta a la vista que será gracias al viaje al Sur que los tekenaars pasen de mero motivo lateral a tema central en unos cuantos óleos de la época. No en vano, será allí, en el Sur, donde algunos paisajistas llegados de los Países Bajos y Francia conciban los mejores lienzos sobre el tema del XVII. Ahora bien, el proceso será lento.

Wolfgang Stechow comenzaba su clásico relato del desarrollo de la «escena italiana» entre los paisajistas holandeses del siglo XVII refiriéndose a los artistas nacidos entre 1595 y $1600^{18}$. Sin embargo, en cuanto uno comienza a estudiar el paisajismo practicado en Roma de la época, es evidente que todo empezó antes.

A fines del siglo XVI y principios del XVII, siguiendo los pasos de Pieter Brueghel el Viejo, de Heemskerck y de Hoefnagel, unos cuantos flamencos y holandeses se aficionaron a recorrer los alrededores de Roma dejando, como aquellos, un testimonio visual de su paso. Carel Van Mander recorrerá los mismos caminos en 1604 pero, ya antes, los Brill y los descendientes del primer Brueghel artista convertirán la representación de sus paseos y escarceos en verdadero subgénero para el arte ${ }^{19}$.

Procedentes de Amberes, Paul y Mattheus Brill llegarán a Roma en los años setenta del siglo XVI. Se asentarán allí gracias a los encargos de la corte papal, llegando con frecuencia a Tívoli. Desde 1590, su taller se convertirá en un imán para los artistas flamencos que deseaban ir a Roma o pasaban por allí. De ahí que no resulte extraño que a un colaborador directo de Paul Brill en la Ciudad Eterna entre 1604 y 1626, Willem van Nieulandt (I) -artista de Amberes nacido en 1584 en el seno de una familia calvinista que emigró a Amsterdam- se le atribuya un paisaje con paisajista realizado en esos mismos parajes ${ }^{20}$.

Del mismo modo, con Jan Brueghel el Viejo - uno de los hijos de Pieter el Viejo, nacido en 1568- se vincula la Cascada de Tívoli con dibujante datada en 1606 y antes atribuida a Paul Brill $^{21}$. Junto a ambos debió viajar un imitador de este último, Sebastiaan Vrancx, nacido en 1573 y que firma un Templo de Vesta en Tívoli con dibujante y una Basilica de Constantino con dibujante ambos de hacia $1600^{22}$. A un hijo de otro de los ayudantes flamencos de Brill, a Pieter Stevens (II), le debemos un nuevo croquis con dibujante en bosque de hacia $1614^{23}$. Finalmente, a Paulus van Hillegaert (I), artista de Amsterdam nacido en 1596 próximo al círculo de Paul 
Brill, se le atribuye un dibujo posterior a 1611 realizado probablemente en Italia en el seno de este grupo de pioneros ${ }^{24}$.

En todos los casos, la figura del artista representado seguía el tipo que Pieter Brueghel el Viejo había puesto de moda a través de dos grabados. Aparecía concentrada, ridícula, dibujando sentada, raramente acompañada, abrumada -podría decirse- por la naturaleza o las ruinas circundantes: es el modelo del «paisajista-testigo». No obstante, las composiciones remitían al modelo cerrado que el propio Brill puso de moda: se tratase del ramaje de los árboles, de las rocas de una cueva o de los muros de un viejo monumento, el espacio cedido al cielo resultaba nulo o muy escaso, y el efecto atmosférico y las referencias bucólicas que se descubren en la obra de Jan Both de 1650, todavía no habían cuajado. No en vano, la «escena italiana» a la manera de Both sólo empezará a despuntar en la década de 1620.

\section{Roma y la Edad Dorada del paisajista testigo}

Los pájaros de bandada. Entre los artistas holandeses que ayudaron a dar forma a la verdadera "escena italiana» del XVII en Roma cabe distinguir tres generaciones. Aunque Stechow apenas le presta importancia, la primera, la de los nacidos entre 1595 y 1600, fue liderada por un artista que no destacó como paisajista, pero ennobleció el tema del artista en el paisaje al atreverse a introducir ese personaje en sus óleos; me refiero a Pieter van Laer, II Bamboccio (1599$1642)^{25}$.

Van Laer fue el líder del grupo de los Bentvueghels o "pájaros de bandada», un conjunto de artistas holandeses bien organizado afincado en Roma desde 1623. La organización se fundó para diversión y ayuda mutua, haciéndose famosa porque sus miembros recibían la denominación de «pájaros» en un acto burlesco en el que eran bautizados con vino ${ }^{26}$. Si hubiesen vivido en el XIX, por su vida disoluta y pendenciera se les habría llamado bohemios. En todo caso, lo interesante aquí es que todos juntos siguieron el consejo de Van Mander de salir al campo a tomar apuntes, llevándose esa maravillosa práctica a Italia.
Aficionado a realizar croquis del natural, Van Laer la representará y desarrollará desde pronto en cuadros como Vista del Campo Vaccino de Roma ${ }^{27}$, que por su tema recuerda a Heemskerck y Brill. Pero también la encontraremos en las obras de otros miembros de la primera generación de Bentvueghels especializados en «escenas italianas», v. g., en la obra de Herman van Swanevelt (1603-1655), apodado 'el Ermitaño'28, o en la de Bartholomeus Breenbergh (antes de 1598 - ca. 1657), apodado el 'Hurón'.

Breenbergh permanece en Roma entre 1619 y 1629, copiando durante ese periodo algunos dibujos de Brill. Además, se sabe de la influencia que sobre él ejerció Poelenburgh (ca. 15951667), discípulo, a su vez, del mismo Bloemaert al que debemos un paisaje rural con dibujante ya citado ${ }^{29}$. Desde el punto de vista pictórico, Breenbergh anticipa algunos efectos de Jan Both $y$, además, sigue aportando ejemplos a la lista de cuadros de artistas en el paisaje. Se ha sugerido que en su Vista idealizada con ruinas romanas, esculturas y un puerto al fondo, pintada a su regreso a Holanda en 1650, la figurilla del paisajista activo quizás desempeña una función moral, porque contrasta con el perezoso joven durmiente de la esquina inferior derecha ${ }^{30}$. Personalmente, no creo que haga falta añadir nada que no esté en el propio cuadro. En él, Breenbergh sólo edulcora viejos recuerdos de lo que debía ocurrir con frecuencia en sus excursiones; a saber, que unos dibujaban mientras otros dormían la fiesta de la víspera.

Los paisajistas franceses de Roma. Entre esos compañeros de excursión comenzarán a coincidir algunos franceses. No en vano, un dato fundamental para entender la presencia y evolución del tema del paisajista en el paisaje en los óleos de los holandeses de Roma del segundo cuarto del siglo XVII, es que entre 1625 y 1650 coincidan allí con Poussin, Lorena y Dughet. Los franceses salían solos o en parejas, pero, más gregarios, los holandeses se aficionaron pronto $a$ ir en grupo. No obstante, en algunos paseos coincidirán todos.

Al respecto, cuenta, por ejemplo, Sandrart que en una ocasión hizo una excursión de Roma a Tívoli para dibujar paisajes con Lorena, Poussin y Van Laer ${ }^{31}$. En este sentido, no extraña que los 
franceses adoptasen como propia la temática inventada en los Países Bajos e introducida en Roma por el círculo de Brill. Podemos encontrar apuntes del tema como Paisaje con dibujante de Nicolas Poussin (1594-1665) de hacia 1635-40, en el que, según su propietario en el siglo XIX, Philippe de Chennevières, el francés no se retrataba a sí mismo, sino a Gaspard Dughet, cuñado suyo y paisajista como él ${ }^{32}$. Pero, sobre todo, podemos disfrutar de varias obras de Claudio de Lorena (ca. 1600-1682) de gran interés.

De Breenbergh y de Brill debió aprender Lorena muchas técnicas, siendo, además, discípulo de un discípulo de Brill, Agostino Tassi. Los dos, Breenbergh y Lorena, coincidieron en los talleres romanos de Brill y Tassi, creciendo juntos en su pintura con el paso de los años y haciendo excursiones con Van Laer. Por todo ello, por lo que aprendió de los flamencos y holandeses, y por la importancia de las excursiones para su trabajo, no extraña que convirtiese el tema del dibujante en el paisaje en parte de su obra.

Esto lo pone de manifiesto, en primer lugar, que algunos de los óleos de Lorena más antiguos que conservamos sean un Idilio. Paisaje con artista dibujando ruinas de los años veinte, y un Molino junto al río con artistas de 1631 -que mencionaré más adelante-33; en segundo lugar, que con el tiempo siga presentando el tema en grabados y bocetos como Un artista dibujando con una segunda figura mirando, del British Museum ${ }^{34} ; \mathrm{y}$, por fin, que todavía a fines de los treinta y principios de los cuarenta continúe recogiendo el motivo en óleos como Artista estudiando la naturaleza del Cincinnati Art Museum $^{35}$ (Fig. 2).

Contemplando sus trabajos y comparándolos con los de aquellos que le preceden parece evidente que la aportación del francés se resume en el mayor protagonismo que concede a las fi-

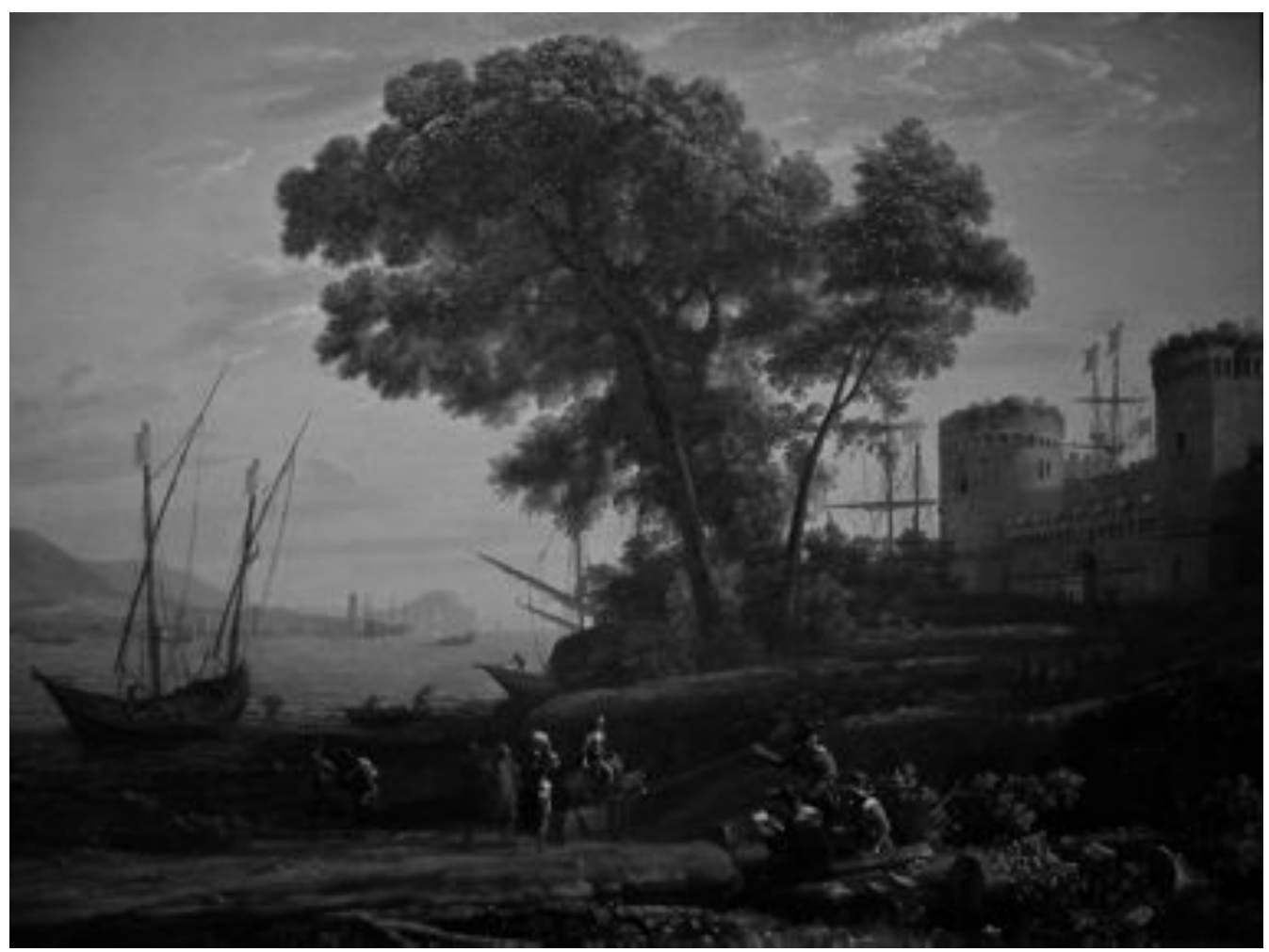

Fig. 2 Claudio de Lorena: Artista estudiando la naturaleza, 1639, óleo sobre lienzo, 78,1 x $101 \mathrm{~cm}$, Cincinnati Art Museum, inv. nr. 1946.102. 
guras de los artistas. Su tamaño y presencia crece hasta un punto que previamente sólo podíamos encontrar en la obra de Valckenborch. Algunos especialistas insisten en que esas figuras fueron pintadas por ayudantes. Sin embargo, dibujos de su mano sueltos o incluidos en el Liber Veritatis nos permiten entender la importancia que tuvieron para un maestro que, no lo olvidemos, en las décadas de los treinta y cuarenta estuvo constantemente tomando apuntes del natural ${ }^{36}$.

Si, por otro lado, aceptamos que en sus óleos las composiciones irán cambiado y la atmósfera y la luz del Sur ganarán espacio, convendremos en que será Lorena el que allane el terreno para que, a la altura de 1650, Jan Both dé forma al mejor cuadro sobre este tema del siglo XVII.

\section{Both \\ Paisaje italiano con dibujante de Jan}

Por edad, nace hacia 1618, Both será uno de los miembros de la segunda generación de paisajistas holandeses especializados en «escenas italianas» que pasen por Roma -generación que Stechow limita a los nacidos entre 1615 y 1630-. En Holanda, parece haber tenido relación con Bloemaert, pater familias del paisajismo de Utrecht del que también fue discípulo el mentado Poelenburgh ${ }^{37}$; y en Roma debió permanecer de 1638 a 1641, coincidiendo con su hermano, con Asselijn y los demás Bentvueghels ${ }^{38}$. Como el resto del grupo, Jan debió aceptar las propuestas estilísticas de Van Laer y, como los más receptivos, debió fijarse en el arte de Claudio de Lorena ${ }^{39}$. Pero, sobre todo, como los otros miembros de esta segunda generación, es decir, como Asselijn, Weenix, Berchem o Dujardin ${ }^{40}$, Both también recalará en el tema del paisajista en el paisaje.

Algunos autores identifican en su Paisaje con dibujante conservado en el Los Angeles County Museum of Art (Fig. 3) el enclave de Ponte Lucano y la Tumba de Plauto -que el pintor pudo conocer en Italia- y lo relacionan directamente con el óleo pintado por Claudio de Lorena en 1639, conservado en el Cincinnati Art Museum, y mencionado antes ${ }^{41}$. Pero lo cierto es que, como el Paisaje italiano con dibujante del Rijksmuseum ${ }^{42}$, Both también debió pintarlo de regreso a su tierra en Utrecht partiendo de apuntes y recuerdos

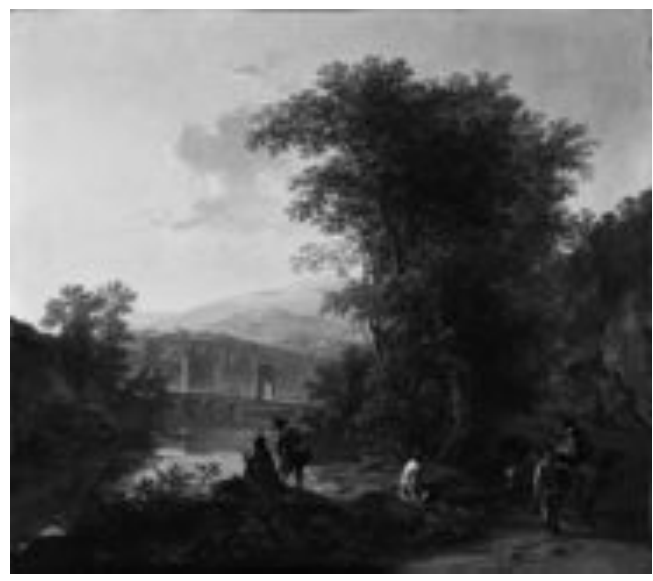

Fig. 3 Jan Both: Paisaje con dibujante, ca. 1650, óleo sobre lienzo, 104,46 x 118,11 cm, Los Angeles County Museum of Art, inv. nr. M. 2009.106.3.

romanos. Que el holandés diese tanta importancia al tema, y, sobre todo, que sus cuadros tuviesen tanto éxito entre sus compatriotas ${ }^{43}$, sugiere el valor del diálogo entre la naturaleza y el hombre que aquí se representa.

Concentrémonos en los personajes del cuadro del Rijksmuseum. Por un lado, la situación del artista o artistas junto al camino italiano y las cargadas mulas parecen remitir, no sólo a Lorena, sino a la idea del viaje y a cierta lejana vivencia. Antes del francés, el tema del camino ya era clave en la obra de los holandeses, que lo repetían en numerosos lienzos y dibujos recogiendo un motivo harto frecuente en la iconografía paisajística de los Países Bajos del Sur. Si tuvo tanto éxito es porque, mediado el siglo, en la tierra natal de Both los viajes habían pasado a ser un elemento que casi determinaba el carácter nacional. En ese mundo holandés agitado por excursiones, incursiones, rutas, traslados y peregrinaciones -mundo del que, por otro lado, se conserva una abundante documentación en forma de literatura periegética y diarios-, se harán famosas las exploraciones romanas de los Bentvueghels ${ }^{44}$, exploraciones que ya comenzaron antes de que Lorena se hiciera famoso.

Sin duda, tanto los franceses, como otros artistas italianos, exploraron también a fondo el tema del viaje; por ejemplo, mientras Lorena lo convierte en algo habitual en su obra a fines de los años treinta y durante los cuarenta, Salvator 
Rosa firmaba cuadros como Paisaje con viajeros preguntando el camino, 1641, de temática y estilo tan cercanos a Both que la crítica no duda en compararlos ${ }^{45}$. En todo caso, más allá de los paralelismos, la referencia geográfica que Both y sus compatriotas le dan al motivo -siempre remiten al paisaje de «Italia» o a enclaves concretosmuestra el valor que los holandeses le concedían a la cuestión.

Desde el punto de vista de la posición temporal del artista en relación con la obra, Both no pinta la escena de su alter ego en el paisaje, ni simultáneamente a que ésta tenga lugar -caso de algunos esbozos de Lorena claramente realizados in situ-, ni anteriormente -profetizando algo que vaya a pasar-; la pinta ulteriormente, es decir, años después y ya de regreso en Utrecht. Ha pasado tanto tiempo que la imaginación juega una función más importante en la obra que cualquier atisbo de inmediata percepción, desempeñando la nostalgia un papel de verdadero motor para su realización. En todo caso, la insistencia de Both en asociar sus paisajes con la geografía italiana también indica el valor que en Holanda debían tener estas obras como auténticas pruebas de viaje.

En la colección del Duque de Bedford de la Woburn Abbey (Bedfordshire) se conserva una pintura de Aelbert Cuyp (Fig. 4) titulada, según los catálogos, o Paisaje cerca de Elten, con un artista dibujando, o Jinetes descansando, uno dibujando (ca. 1652-1653, óleo sobre lienzo, 19 x $32 \mathrm{~cm}$ ). La obra arroja algo de luz sobre este aspecto porque en los apuntes previos a su realización -apuntes tomados del natural durante

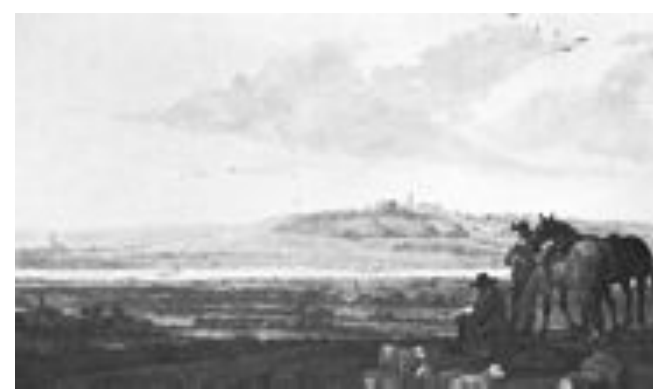

Fig. 4 Aelbert Cuyp: Paisaje cerca de Elten, con un artista dibujando, ca. 1652-1653, óleo sobre lienzo, $19 \times 32 \mathrm{~cm}$, Woburn Abbey (Bedfordshire), colección del Duque de Bedford. un viaje realizado entre 1651 y 1652 y conservados en el Instituto Holandés de París con el título Vue de Hoog-Elten et Laag-Elten, près de Clèves- Cuyp muestra la misma campiña sin el dibujante. Lo que se descubre contrastando ambos trabajos es el método de Cuyp, que introducía a posteriori su propia figura y la de otros personajes en el paisaje ${ }^{46}$.

El dato carecería de valor para nosotros si no se hubiese sugerido en varias ocasiones la transformación del estilo de Cuyp a la luz de la obra de Both, la conexión entre su contraluz y las atmósferas doradas, y la proximidad cronológica de ambos $^{47}$. Sin duda, Cuyp partía con mayor frecuencia que Both de esbozos del natural, y su paisaje se localiza «cerca de Elten» mientras el de Both no parece situarse en ningún lado concreto a parte de la genérica «Italia» ${ }^{48}$. Sin embargo, eso no debería hacernos olvidar que Both al pintarlo quería remitir a cierta «experiencia italiana».

Both se llevó a Holanda una gran cantidad de bocetos y notas de su etapa romana. Conservamos varios que se han relacionado con el cuadro que nos interesa ${ }^{49}$. Observándolos parece claro que en lo que finalmente pintó hay una elipsis del recuerdo que, a la manera del monograma sintético, vincula muchos lugares visitados a dos o tres elementos. Sin embargo, también saltan a la vista los muchos caminos recorridos y la vivencia al aire libre.

Como en el caso de Lorena, en alguna ocasión se ha sugerido sin pruebas que eran otros artistas los que se encargaban de sus pequeñas figuras ${ }^{50}$. Al contrario, observando estos croquis parece que el método de autoincorporación de Cuyp -que subraya el proceso reflexivo y de introspección que realiza todo viajero cuando, al mirar atrás, recuerda los lugares por los que ha pasado y comienza a pensarse a sí mismo en relación con ellos- no le debía resultar ajeno a Both. Al respecto, vislumbro una especie de recorrido lento pero invariable que va del Puente en un paisaje montañoso con cascada conservado en Munich y el Paisaje italiano con carretera del Museo Nacional de Suecia, pasando por los dos Puentes guardados en Dublín y Londres ${ }^{51}$, hasta culminar en el óleo del Rijksmuseum que nos ocupa (Figs. 5-8). Por el camino se ha perdi- 


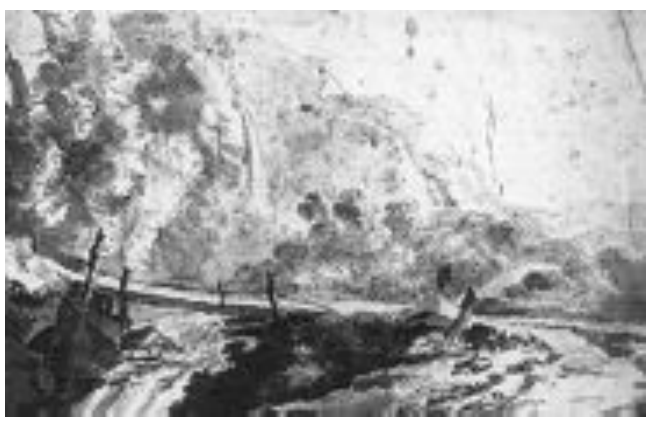

Fig. 5 Jan Both: Puente en un paisaje montañoso con cascada, s.d., lápiz y aguada sobre papel, 18,7 x $29 \mathrm{~cm}$, Munich, Staatliche Graphische Sammlung, inv. nr. 1823.

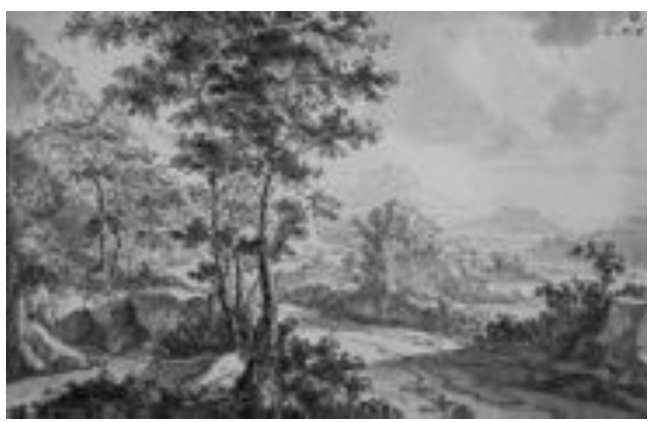

Fig. 6 Jan Both: Paisaje italiano con carretera, s.d., lápiz, tinta marrón y aguada sobre papel, de 20,6 × 32,2 cm, Estocolmo, Nationalmuseum, inv. nr. NMH 127/1866.

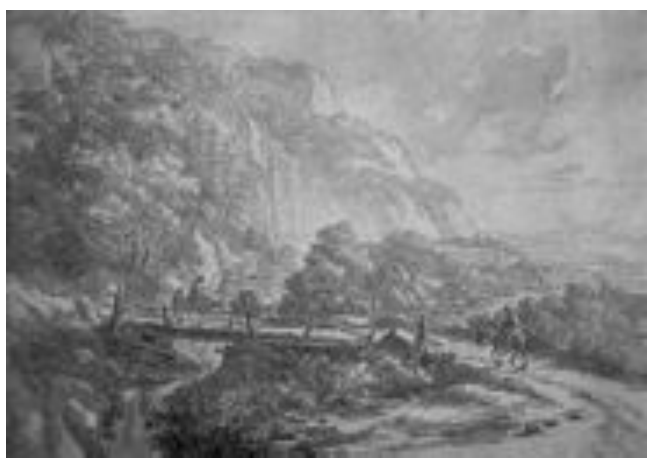

Fig. 7 Jan Both: Puente en un paisaje montañoso con cascada, s.d., dibujo a sanguina sobre papel, $18,4 \times 26,4 \mathrm{~cm}$, Dublín, National Gallery, inv. nr. NGI.2020.

do mucha espontaneidad y a todas luces la naturaleza se ha tornado mera composición. Sea como fuere, puesto que algunos dibujos debieron ser realizados en Roma ${ }^{52}$ parece justificado afirmar que detrás del Paisaje italiano con dibu-

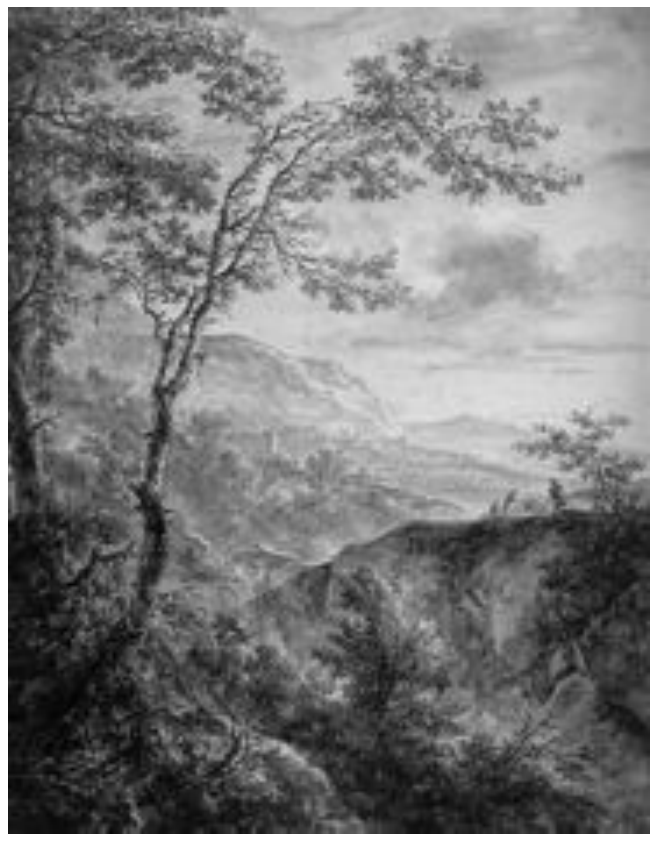

Fig. 8 Jan Both: Paisaje montañoso con cascada, s.d., lápiz sobre papel, 39,3 x 30,8 cm, Londres, British Museum, inv. nr. 1895,0915.1126.

jante al óleo de Amsterdam hay más vida de lo que se suele decir.

De hecho, por paradójico que resulte, contemplándolo parece claro que la historia de este «artista en el paisaje» es la historia del intento de devolver la vida al paisaje y al artista. La muerte de ambos, de paisajista y paisaje, se produce en el momento en que el frenesí realista obliga al artista a omitir su presencia apostando por la aporética ilusión de la descripción que la niega. Ocurre que ese proceso de objetivación del mundo presidido por la imitación nunca satisfizo del todo al arte. La esencia misma del paisajismo, como fruto de la emoción, de la fuerza, de la atracción y hasta del sentimiento de comunión del sujeto para con el mundo, obliga desde los comienzos del género a buscar otra solución. Al fin y al cabo, ¿quién habla cuando el paisaje descriptivo se muestra en todo su supuesto candor? ¿El artista y su objetiva visión? ¿La naturaleza a través del artista? ¿La sabiduría universal? ¿O el espíritu de una época mostrando su fulgor? Nunca será posible averiguarlo por la sencilla razón de que el arte analítico y realista es 
la destrucción de todo origen, de toda mirada y de todo narrador, es ese lugar neutro, compuesto, oblicuo, al que van a parar nuestro sujeto o el blanco-y-negro en donde acaba por perderse toda identidad, comenzando por la propia identidad del cuerpo que pinta.

Con el paisaje siempre ha sido así: en cuanto una porción del territorio pasa a ser descrita, no para actuar con o sobre ella, sino con fines intransitivos, se produce una ruptura, la mirada cree perder su origen, y el artista entra en esa su muerte, que le da vida a la descripción, pero no necesariamente al paisaje ${ }^{53}$. Por tanto, introducir al artista en la obra puede presentarse como el intento de resolver la cuestión, de reanimar al país como paisaje recordando el sentimiento vivo del propio pintor.

Edulcorado en el taller, también el 'modo' de representar la naturaleza en ese paisaje desprende sentimiento. Esa fuerza tranquila se expresa mediante la iluminación dorada que baña todo el cuadro y afecta para bien al resultado. Si resulta así es porque, como sostuvo Sandrart, Both pintó la luz con tal perfección que era posible reconocer en sus cuadros la hora exacta del día a que hacían referencia, y porque los pequeños personajes -desplazados del centro de atenciónrefuerzan el protagonismo de la iluminación.

De hecho, la obra del de Utrecht es importante en este punto porque representa la asimilación del arte italianizante por los paisajistas del Norte. Efectivamente, además de convivir con holandeses, Both trabajará con el citado Poussin, con Lorena y con Dughet, y participará con ellos en grandes proyectos decorativos para el Buen Retiro de Madrid ${ }^{54}$. Para insistir en su relación con Lorena, la crítica recuerda los vínculos estilísticos entre el trabajo de Both y el Molino junto al río de Boston (Fig. 9), que el francés debió pintar unos meses antes de coincidir con el holandés, en $1631^{55}$. Se afirma unánimemente que, en ese cuadro se perciben, junto a una de las primeras

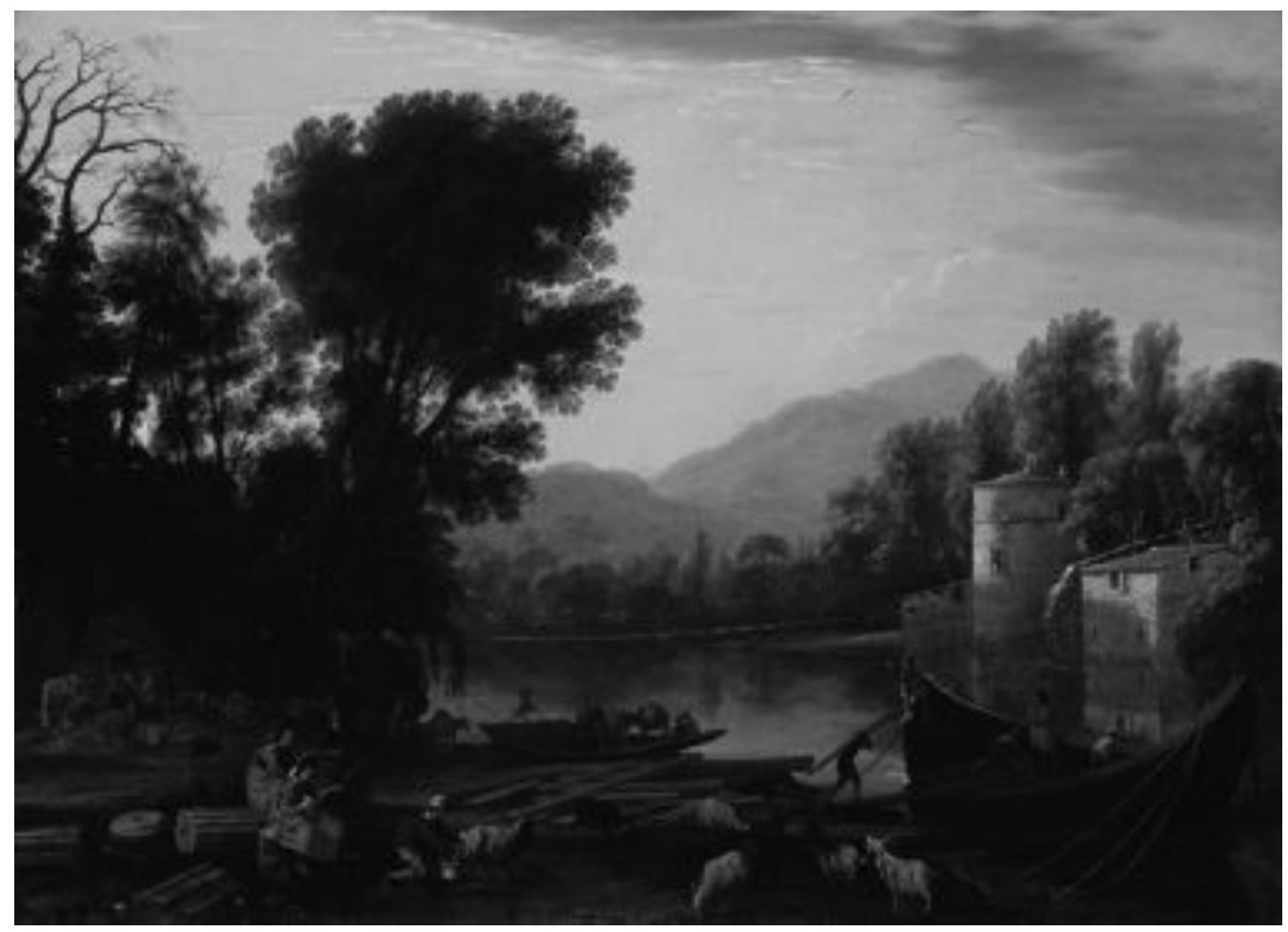

Fig. 9 Claudio de Lorena: Molino junto al río, 1631, óleo sobre lienzo, 61,6 x 84,5, Boston, Museum of Fine Arts, inv. nr. 44.72. 
atmósferas doradas que harán famoso a Lorena, detalles como las ramas de los árboles de la izquierda, la iluminación de los edificios de la derecha o el tratamiento atmosférico de las montañas del fondo, que presagian la obra de Jan Both.

Lo que a veces no se comenta es el motivo más obvio de la cercanía entre el trabajo del holandés y el del francés: que en ambos casos hay figurillas que representan artistas y dibujantes sentados ${ }^{56}$. ¿Por qué las de Lorena -de las que una parece un autorretrato del pintor mirando hacia nosotros en una actitud que recuerda el hallazgo iconográfico de Valckenborch ${ }^{57}$ - son distintas de las de Both?

\section{El artista en el paisaje como figura del "otium»}

Paisaje italiano con dibujante de Both representa la fusión de dos tradiciones. Si en la composición y la luz remite hasta cierto punto a un Lorena al que incluso supera, las figuras y el realismo botánico nos ponen en contacto con una tradición norteña que los franceses habrían aprendido en sus excursiones con los Bentvueghels. El resultado, englobando el punto de vista realista y viajero holandés y el contemplativo e idealizante francés, puede interpretarse de varios modos.

Lecturas moralistas. Por un lado, a diferencia de los cuadros de Lorena, al leer los de Both podríamos recordar las violentas interpretaciones religiosas según las cuales nada hay de espontáneo en motivos como el amanecer o la naturaleza de los paisajes nórdicos porque dichos elementos en ese lugar tienen un sentido profundo que remite a cierta visión protestante del mundo.

Efectivamente, lejos de la austera visión del calvinismo que se nos ha ofrecido hasta ahora, algunos holandeses abiertamente protestantes como Huygens mostraron un evidente amor por la naturaleza en general y por el paisaje rural en concreto. El mismo Calvino en su Institutio Christianae Religionis (Ginebra, 1545) contemplaba el mundo natural con ojos de físico-teólogo. Los árboles y el sol, los insectos y las aves, eran una muestra de la bondad de Dios, e incluso podían pintarse paisajes como obras de tema inocente que sencillamente servían para disfrutar de su imagen ${ }^{58}$. Al contrario, siendo lo divino irrepresentable, resultaba perjudicial demorarse en las imágenes heredadas de lo sagrado, que ya sabía manifestarse en lo tangible que nos rodeaba. Según algunos historiadores, arraigada en Holanda, esa visión admirada de las cosas concretas favorecería, no sólo el desarrollo del empirismo, sino del nuevo paisajismo del XVII. Más exactamente, el tránsito del manierismo flamenco al realismo holandés -ejemplificado, sin ir más lejos, por la obra de Esaias van de Velde-, sólo sería posible gracias a la escala de valores de los hugonotes ${ }^{59}$.

Aun siendo en parte interesante, sin embargo, esta interpretación del éxito del nuevo género resulta bastante limitada $y$, en cuanto nos detenemos a analizar la cuestión con cierto cuidado resulta evidente que la teología natural protestante, ni pudo motivar unilateralmente la eclosión del nuevo paisajismo, ni aportó lo suficiente para interpretarlo correctamente.

En primer lugar, en los siglos XVI y XVII en los Países Bajos del Norte y del Sur encontramos promotores de la idea de la sencilla naturaleza como "Gran Libro de Dios» que, sin embargo, eran católicos -escritores de la talla de Anna Bijns (1493-1575), Hendrick Laurensz Spiegel (1549-1612) o Joost van den Vondel (15871679) $-^{60}$. De hecho, si resultase correcto limitar la eclosión del nuevo paisajismo al desarrollo del calvinismo, sería obligado mostrar la distancia entre el discurso físico-teológico calvinista y el católico, y subrayar cómo sólo el protestante habría sido capaz de promocionar cierta pintura realista de paisaje ${ }^{61}$. Sin embargo, lo cierto es que, en cuanto nos detenemos en ambos discursos, se descubre con facilidad su origen común en la más amplia tradición retórica y estereotipada cristiana62, llegando, incluso, a ser posible -aunque no creíble- defender la relación entre catolicismo contrarreformista y desarrollo del paisajismo pictórico ${ }^{63}$.

A pesar de lo dicho, cierta interpretación religiosa podría seguir defendiéndose si, superada la división entre calvinismo y catolicismo, se mostrase un vínculo directo entre el simbolismo físico-teológico cristiano, en general, y el desa- 
rrollo del nuevo paisaje; más aún, en el caso de Both, de defenderse alguno, ese planteamiento sería el único correcto porque, al haber trabajado en Roma entre católicos confesos, ceñirse a una lectura calvinista siempre parecería algo limitado, y porque, desde 1650, los compradores católicos de cuadros de paisaje en Holanda fueron tan abundantes como los protestantes ${ }^{64}$.

Desde luego, teología natural siempre hubo. La encontramos en casi toda Europa desde la Edad Media ya antes de la Reforma -el Canto de las Criaturas de San Francisco, el Itinerario de la mente a Dios de San Buenaventura o el Tratado del amor de las criaturas de Raimundo Sibiuda, son sólo algunas muestras-; y la encontraremos de nuevo reforzada a fines del siglo XVII y a lo largo del XVIII tanto en el Sur católico como en el Norte protestante -la Teodicea del protestante Leibniz, y el Espectáculo de la Naturaleza del jesuita Pluche, insisten por igual en la idea del Soberano Arquitecto ${ }^{65}$-. Lo mismo cabe decir del protagonismo del homo viator, verdadero leitmotiv del pensamiento cristiano. Contando ya con el precedente en la ascética y la mística del pasado, lo que parece cuajar con fuerza y repetirse sólo desde el siglo XVI es esa figura del pequeño viajero anónimo en el ámbito iconográfico.

Sabemos que un siglo antes de que Both pintase su cuadro, en tiempos de Patinir y los Brueghel, ese tema se asociaba con la propia experiencia del viaje y con las decisiones que debemos tomar a lo largo de la vida ${ }^{66}$. En este sentido, desde este punto de vista general, sí cabe suponer cierta carga moral en estas imágenes. Sin embargo, me da la impresión de que, salvo casos bien documentados, con las pinturas de Both, tampoco sería correcto limitarse a interpretaciones de esta clase. En primer lugar, porque carecemos de datos; pero, sobre todo, porque tenemos una idea bastante aproximada de lo que los Bentvueghels y los compradores de sus cuadros, esperaban de esos paisajes.

Entramos así en la interpretación más interesante del cuadro que nos ocupa, la interpretación lúdica y sensual compatible, hasta cierto punto, con la lectura moral.

Lecturas lúdicas. Para poderla presentar conviene comenzar subrayando la figura del dibu- jante acompañado y de los pastores con sus cabras en el gran cuadro de Both. Al fin y al cabo, ¿no eran esos pastores con cabras el elemento que remitía entonces a la bucólica imagen de la Arcadia? Como ya se ha comentado, la crítica especializada ha indicado con frecuencia que en Utrecht Jan Both estudió con Abraham Bloemaert ${ }^{67}$. Lo que no resulta tan habitual es recordar, contemplando la obra de Both, que Bloemaert fue uno de los artistas de Utrecht que pusieron de moda en Holanda el paisaje rústico de pastores descansando. En una serie de grabados publicada con la ayuda de su hijo en Utretch entre 1620 y 1625, no sólo se representaban muchos pastores y personajes sentados en el campo, sino que, por si cabía duda acerca del tema, se incluían textos donde se hacía referencia al Otio delectant, es decir, al disfrute y al placer.

Desde luego, su lectura resultaba ambigua. Mientras, siguiendo un patrón moral tradicional, se nos advertía contra la vagancia, la mayoría de las imágenes y algunos textos tendían a enfatizar los aspectos positivos del otium. El grabado de un cabrero descansando resultaba especialmente gráfico al respecto ${ }^{68}$. Bajo la ilustración, un texto en latín rezaba: "Non adeas aulam, qui diligis otia mentis: Haec nemus umbrosum, vel tibi caula dabunt», que se podría traducir como «No te acerques a la Corte, tú que amas el ocio de la mente; un pasto con sombra o un simple corral ya te darán esto». Avanzado el siglo XVII, los ecos de las clásicas arengas de la Stultitiae laus de Erasmo de Rotterdam (1509) o del Menosprecio de Corte y alabanza de aldea de Antonio de Guevara (1539) todavía resonaban, recogiendo, en el fondo, un tópico ya presente en los versos de Horacio.

Sin duda, podríamos exagerar esta bucólica visión de Paisaje italiano con dibujante de Both negando la interpretación moralista y destacando el grupo de pastores con cabras y las referencias arcádicas. En todo caso, aunque no creo que convenga limitar las referencias al camino y al viaje para subrayar sesgadamente el papel del ocio y la contemplación, no tengo duda de que ahora, a diferencia de los cuadros de Patinir en los que se ponía más énfasis en el homo viator, la presencia de los pastores descansando y el ar- 
tista dibujando relajado decanta el sentimiento que provoca el cuadro en esta otra dirección.

Como ha dicho un reputado especialista:

Pleasure, not preaching, I believe, constituted the chief appeal of rural landscapes for viewers of the seventeenth century, and the varieties of pleasure and the way in which they were expressed in landscape images are recurring themes ${ }^{69}$.

Al menos en parte, hacia 1650, los compradores holandeses de paisajes todavía debían recordar la interpretación moralista de los caminos y los viajeros que se había estilado en Flandes en el siglo XVI; además, no ya la obra de los Brueghel, sino la de un compañero de excursión de Both, el mismísimo Poussin, ha sido interpretada en clave estoica con sólidos argumentos a favor $^{70}$. Sea como fuere, desde el punto de vista de los Bentvueghels, el valor de estos paisajes italianos debía decantarse hacia lo mundano.

Desde el punto de vista del artista creador, es sabido que el grupo de holandeses romano fue amonestado en varias ocasiones por su vida disipada y por realizar ritos heréticos de adoración al vino; al respecto, quizás no esté de más recordar que el hermano de Both murió tras caer a un canal en Venecia en extrañas circunstancias. Teniendo en cuenta esto, parece evidente que la mirada relajada de Both en sus paisajes italianos con dibujante no necesita justificación más allá del reflejo del estado egosintónico y de comunión con las cosas, o de la simple celebración de la vida. Con sus cuadros, el holandés remitía a una vieja tradición, aceptada en Holanda gracias a Mander, Visscher y Bloemaert, que convirtió el paisaje idealizado en una especie de «área de descanso».

$Y$, desde el punto de vista de los clientes y compradores holandeses, su lienzo se debía comportar como el correlato visual de un poema de Pieter Verhoek (1633-1702) fechado en esos mismos años. En el mismo, Verhoek celebraba un ciclo de paisajes italianos de Adam Pynacker (1622-1673) pintado hacia 1665 para un magnate de Amsterdam Ilamado Cornelis Backer. El paralelismo con el caso que nos ocupa resulta notable porque Pynacker es considerado con
Dujardin miembro destacado de la segunda generación de paisajistas italianizantes liderada por Jan Both ${ }^{71}$, y porque en los versos de Verhoek se presentaba al comprador de la obra contemplando las vistas italianas de Pynacker con las siguientes palabras:

Aquí podrá el Sr. Backer, cuando los árboles aparezcan desprovistos de hojas / Y el yermo campo desaparezca abrumado por las montañas / De nieve a la deriva, contemplar las pobladas copas, / El follaje verde, como un Verano para la vista. I Ante él, cansado por los trabajos realizados, podrá colgar su arco recreándose en la contemplación $n^{72}$.

Algunos cuadros de Pynacker han sido comparados directamente con el Paisaje italiano con dibujante de Both ${ }^{73}$, e incluso los decorados a que se refiere Verhoek han sido relacionados con un Paisaje italiano con pescadores del Museo Boijmans que, por su camino, sus aguas, su marco arbóreo y su luz, se muestra plenamente deudor del arte de Jan Both ${ }^{74}$. Aplicando a los cuadros de este último lo que Verhoek destacó en el siglo XVII de los Pynacker, resulta fácil deducir lo que tanto el artista como sus clientes debían pensar y esperar de sus paisajes. Como en ese caso, la vista sureña con dibujante de Both representaba el follaje verde como un pequeño «Verano para la vista» y, por si cabe alguna duda acerca de la ociosa actividad y las sensaciones que se proponían, introducía nostálgicamente su pequeño artista-doble «recreándose en la contemplación».

Del ocio desinteresado a lo lúdico interesado. Sin duda, el resultado en principio parece remitir a la reflexión de Schopenhauer sobre la experiencia estética, aquella en la que el filósofo alemán afirmaba que, cuando, abandonando el ajetreo diario, uno desiste del modo habitual de enfocar las cosas y cesa de verlas desde el punto de vista cotidiano, no considera ya el cuándo, el dónde o el por qué, sino que consagra toda la escasa fuerza de sus sentidos a la intuición, enfrascándose por entero a ella y dejando que la consciencia quede plenamente colmada por la serena contemplación. No obstante, a diferencia de semejante disolución del Yo, lo que muestra la obra de Both es precisamente la negación de 
la expresión del alemán según la cual uno se pierde en esos objetos íntegramente ${ }^{75}$.

Como salta a la vista, Both nunca se perdió del todo. La prueba: que se retrata a sí mismo «mirando» ese maravilloso esplendor. Al fin y al cabo, ¿qué mejor modo de representar la comunión que pintar el paisaje sin dejar de pintar a un empequeñecido pintor?

Esto pone de manifiesto que el «sentido» primero del cuadro de Both no fue otro que lo que él mismo «sintió»: la nitidez de las lindes del bosque, las aguas gozosas, el imponente macizo rocoso, el racimo de casas al fondo, el alegre nerviosismo de los viajeros, la piel acariciada por la hermosa luz del solsticio de verano, la naturaleza espléndida, el calor y las bondades del entorno, el deseo de quedarse allí para siempre, el maravilloso sentimiento de amable comunión... Pero, frente al desinterés o el carácter avolitivo con que Schopenhauer asociaba la experiencia del paisaje, su cuadro, sólo al ser colocado en la sala de alguna casa urbana del Norte, adquiría su verdadero valor, su evidente papel compensador.
Hace años, la famosa tesis de Ritter mostró que la emergencia del sentimiento estético de la naturaleza como paisaje nacía del divorcio del hombre con la naturaleza. Según el alemán, ese divorcio habría sido promovido por una filosofía y una ciencia obsesionadas por estudiar una naturaleza «objetivada» y separada del contexto de la existencia y de la intuición ${ }^{76}$. Siendo esto en parte cierto, cabe no obstante recordar el importante lugar que en ese proceso debió ocupar el trabajo y las alienantes tareas urbanas. Como muestran los versos de Verhoek, los paisajes italianizantes de las casas de las ciudades de Holanda representaron para los nórdicos de la época el momento de la reconciliación, el momento en el que el Yo, tras percibir el mundo hostil consciente de su separación, caía de nuevo rendido ante el espectáculo ajeno pero cercano de la $\mathrm{Na}$ turaleza del Sur. Y, por si quedaba alguna duda sobre la belleza como felicidad y sobre el estado de paz y bienaventuranza que trataba de presentar, Both colocaba a su pequeño artista alter ego relajado contemplando el escenario de la recuperada comunión ${ }^{77}$.

\section{NOTAS}

${ }^{1}$ Lo que se cita entre comillas procede del clásico de Wolfgang Stechow: Dutch Landscape Painting of the Seventeenth Century, London, Phaidon, 1966, pág. 7. En general, hace años que la historiografía debate en torno al significado o falta de significado de los paisajes. En los márgenes de ese debate, el de las staffagenfiguren o personajillos de esos paisajes. Tres investigadores representan las posiciones más argumentadas y serias sobre el tema: Svetlana Alpers, Reindert L. Falkenburg y, entre ambos, Walter G. Gibson. Una incompleta panorámica puede encontrarse en Hans-Joachim Raupp: «Zur Bedeutung von Thema und Symbol für die holländische Landschaftsmalerei des 17. Jahrhunderts» en Jahrbuch der Staatlichen Kunstsammlungen in Baden-Württemberg, 17, 1980, págs. 85-110, ahora actualizado y resumido en Hans-Joachim Raupp: «Thema und Bedeutung» en Landschaften und
Seestücke. Niederländische Malerei des 17. Jahrhunderts der SØR Rusche Sammlung, Münster, LIT Verlag, 2001, págs. 24-28, especialmente, págs. 27 y 28. Sea como fuere, el motivo específico del paisajista en el paisaje apenas ha sido estudiado.

${ }^{2}$ V. Federico L. Silvestre: «El pintor como narrador. Génesis flamenca del paisajismo intradiegético» en Historia, Imagen, Lenguaje, Santiago de Compostela, Universidad de Santiago de Compostela, 2013.

${ }^{3}$ En holandés: Italiaans landschap met tekenaar, ca. 1650, gran óleo sobre lienzo de $240 \times 187 \mathrm{~cm}$, firmado "JBoth f.», Rijksmuseum, inv. SK-C109. Sobre el mismo, véanse: Cornelius Hofstede de Groot: Beschreibendes und kritisches Verzeichnis der Werke der her vorragendsten hollandischen Maler des XVII. Jahrhunderts, vol. 9 [dedicado a Johannes Hackaert, Nicolaes Berchem, Karel Du Jardin, Jan Both, Adam Pijnacker], Esslingen a N., P. Neff..., 1907, 87 [reimpreso en 1976 con el tomo 10]; Wolgang Stechow: Op. cit., 1966, pág. 155; James D. Burke: Jan Both: paintings, drawings, and prints, Michigan, University of Michigan, Garland Pub., 1976, págs. 180-18, cat. nr. 11; Peter C. Sutton: Masters of 17th-century Dutch landscape painting, Amsterdam / Boston, Rijksmuseum \& Museum of Fine Arts, 1987, pág. 279, cat. nr. 15; y Jakob Rosenberg y Seymour Slive en "Los pintores italianizantes» en Arte $y$ arquitectura en Holanda, 1600-1800, Madrid, Cátedra, 1994, págs. 301-318, especialmente, pág. 311-312.

${ }^{4} \mathrm{~V}$. James D. Burke: Jan Both. Op. cit., 1976, pág. 34. En estas páginas apenas mencionaré a Andries porque Malcolm R. Waddingham ya ha mostrado lo sobrevalorada que está esa figura menor («Andries and Jan Both in France and Italy» en Paragone 15, $\mathrm{n}^{\circ}$ 171, 1964, págs. 13-43). Dada la brevedad de su vida, su colaboración con Jan, citada por Sandrart, no debió ser excesiva. De hecho, cuando Jan pintó 
en Holanda su Paisaje italiano con dibujante, después de 1650, Andries llevaba años criando malvas.

${ }^{5}$ Efectivamente, después de haber sido aclamada durante más de un siglo, la obra de Both empezará a ser criticada a comienzos del XIX. Leyendo mucho es fácil percibir este cambio: al tiempo que se reconocía la labor de Vermeer o los realistas holandeses, los promotores del arte idealista e italianizante como Both comenzaron a ser criticados. Los artífices del giro serán, sobre todo, los muy influyentes Constable, Ruskin y Thoré. La famosa crítica de Constable a Jan Both de 1836 se reproduce en John Constable's Discourses, Ipswitch, Suffolk Records Society, 1970, pág. 56. La de Ruskin de 1843, en «Of Truth of Vegetation», Modern Painters, New York, National Library Association, 1873, tomo 1, (Sec. VI. Chapter I, § 22), pág. 398; y la de T. Thoré (que firma como W. Burger) en Musées de la Hollande. Amsterdam et La Haye, études sur l'école hollandaise, Paris, Renouard, 1858, I, págs. 133$134,149,152-153$ y 268 , que manifiesta su falta de interés por la obra de Both y califica alguno de sus cuadros de «sorte de pastiche de Claude» (pág. 152). Lógicamente, a medida que fue pasando de moda, bajaron los precios de sus obras en el mercado (sobre esto último, véase Stechow, Op. cit., 1966, pág. 147. Stechow ha sido el historiador que más ha hecho por rehabilitar la fama de los paisajistas italianizantes holandeses en general, y de Jan Both en concreto (véase, W. Stechow: «Jan Both and the Re-Evaluation of Dutch Italianate Landscape Painting» en Actes du XVIIme Congres International d'Histoire de l'Art [Amsterdam, 2331 juillet, 1952], La Haye, Imprimerie nationale des Pays-Bas, 1955, págs. 425-452). Un resumen sobre la caída en desgracia de Jan Both y los demás artistas nórdicos italianizantes en Jakob Rosenberg y Seymour Slive en «Los pintores italianizantes» en Op. cit., 1994, pág. 301.

${ }^{6}$ V. Wolfgang Stechow, Op. cit., 1966, pág. 154, lo llama «leading master». Repite estas palabras James D. Burke: Jan Both. Op. cit., 1976, pág. 21.

7 Ya Hofstede de Groot, 1907, 87, en el primer catálogo riguroso sobre Both consideró que ésta era su «obra maestra».
${ }^{8}$ La primera catalogación seria de su obra se debe al citado Hofstede de Groot: Op. cit., 1907. La siguiente, la de James D. Burke, 1976, menciona 129 pinturas y 48 dibujos. Un balance general en castellano en Jakob Rosenberg y Seymour Slive en «Los pintores italianizantes» en Op. cit., 1994, págs. 310-313.

${ }^{9}$ V. Friedrich Nietzsche: «Miscelánea de opiniones y sentencias» en $E$ / viajero y su sombra, Segunda Parte de Humano, demasiado humano, § 177, Madrid, Edaf, 1999, pág. 80. 63.

${ }^{10}$ V. J. Burke, Op. cit., 1976, pág.

${ }^{11}$ El primer entrecomillado remite al citado W. Stechow: Dutch Landscape Painting, Op. cit., 1966, pág. 7; el segundo a Peter Sutton: El Siglo de Oro del paisaje holandés, Madrid, Fundación Thyssen-Bornemisza, 1994, pág. 20.

12 Al respecto, véase, sobre Brueghel, Jean-Marc Besse: "La Tierra como paisaje: Brueghel y la geografía» en La sombra de las cosas. Sobre paisaje y geografía, Madrid, Biblioteca Nueva, 2010, págs. 70 y ss.; y sobre Brueghel y los demás, Federico L. Silvestre: «El pintor como narrador. Génesis flamenca del paisajismo intradiegético» en Historia, Imagen, Lenguaje, Op. cit., 2012.

${ }^{13}$ Esto lo explica Hessel Miedema en su edición inglesa de las mismas Vidas, versión titulada The lives of the illustrious Netherlandish and German painters, Doornspijk, Davaco, 1996, pág. 98, nota 15. En el original la referencia a las pequeñas historias aparece en Het Schilderboeck, Haarlem, 1604, fol. $37 \mathrm{v}$.

${ }^{14}$ Originalmente, El fundamento del noble arte de la pintura de Van Mander se titulaba: Den grondt der edel vry Schilder-const (ahora editado y comentado por Hessel Miedema, 2 vols., Utrecht, Haentjens Dekker \& Gumbert, 1973). Contamos con una versión en inglés de esta obra de Elizabeth A. Honig: The foundation of the noble free art of painting, New Haven, Yale University Press, 1985. En todo caso, aquí sigo la traducción al castellano incluida en Christopher Brown: «La primera época del paisaje holandés. Haarlem y Amsterdam, 1590-1650» en Los Paisajes del Prado, Madrid, Nerea, 1993, págs. 131-132.

15 Como artífices de obras que introducen artistas en el paisaje, Peter
Sutton (Op. cit., 1994, pág. 86) citaba ya a Pieter Brueghel el Viejo, Hoefnagel, Valckenborch, Claes Jansz Visscher (deduzco que se refiere al joven), Jan Van de Velde, Allaert van Everdingen, Jan Lievens, Rembrandt y Asselijn. Mientras, Wolfgang Stechow (Op. cit., 1966, págs. 8 y 190, nota 27) mencionaba tan solo a Jan Both, Joris van der Haagen y Aelbert Cuyp. Supongo que, al nombrar a Allaert van Everdingen, Sutton se refería a su Dorpsgezicht [Vista de pueblo], 1631-1675, 12,1 x $18 \mathrm{~cm}$, aguada sobre papel, Rijksmuseum, inv. RP-T-1889-A-2031 (entre otros); que al mencionar a Jan Lievens, pensaba en Boslandschap met ruiter en tekenaar [Paisaje boscoso con jinete y dibujante], 1525-1660, 11,2 x 17,6 cm, lápiz y papel, Rijksmuseum, inv. RPT-1899-A-4292, que también se asocia a Govert Flinck-; que al citar a Visscher debía pensar en Visscher el Joven (que, siguiendo los pasos de su padre, firma el original para el grabado de la Kerck tot Sloten [Iglesia de Sloten] de una nueva serie de los Plaisante Lantschappen, que incluye dos dibujantes, de ca. 1648-1650), y que al mentar la obra de Rembrandt tenía en mente el grabado: Boerderij en stallen, met een zittende tekenaar [Granja y establos con dibujante sentado], 1643-1647, $12,9 \times 20,8 \mathrm{~cm}$, Rijksmuseum inv. RPP-OB-278, Colección J. de Bruijn-. La pieza de Joris van der Haagen citada por Stechow debe ser su Gezicht in de omgeving van Doorwerth [Vista de los alrededores de Doorwerth] 1650, 19,5 x 25,9 cm, lápiz y papel, Rijksmuseum, inv. RP-T-1884-A-342. No he logrado averiguar a qué obra de Jan van de Velde (1593-1641) se refiere Sutton y me pregunto si no pensaría en una de Esaias Van de Velde, primo de Jan, que citaré luego. Por motivos cronológicos, de las obras de Both, Asselijn y Cuyp hablaré también más tarde.

${ }^{16}$ Cabe insistir, después de estudiar el tema con cierto detenimiento, en que las firmas citadas en la nota anterior son sólo las más conocidas de una larga lista de artistas que representaron el paisajista en el paisaje. Como muestran Peter Schatborn y Judith Verberne en Drawn to warmth: 17th century Dutch artists in Italy, Amsterdam / Zwolle, Rijksmuseum \& Waanders Publishers, 2001, la mayoría de los holandeses que se recreen en el tema pasará por Italia. A estos me referiré en 
un momento. En todo caso, hubo otros que no fueron a Italia y que, aunque no son citados por Stechow y Sutton, también dibujaron o pintaron artistas en el paisaje. El archivo digital del Instituto Holandés de Historia del Arte [Rijksbureau voor Kunsthistorische Documentatie, en adelante, RKD] nos permite añadir, a los mentados antes, otros menos conocidos. Con obras anteriores a 1650, aparecen Abraham Bloemaert (pues el versátil y longevo pintor manierista de Utrecht fue también autor de un boceto de dibujante entre casitas rurales de 1595-1605 conservado en el Schlossmuseum de Weimar, inv. 4492), Paulus Willemsz. van Vianen (holandés autor de un dibujo de dibujante en paisaje boscoso de entre 1600-1610 realizado probablemente antes de su visita a Italia y conservado en la Fundación Custodia, Col. F. Lugt), París, inv. 5953A), Esaias van de Velde (el gran paisajista que forma con Goltzius y Avercamp la escuela realista de Haarlem y firma un cuadrito que incluye dibujante titulado Landschap met een kerk [Paisaje con una iglesia], de entre 1610-1619, óleo sobre tabla de $36,5 \times 48,9 \mathrm{~cm}$, vendido en Sotheby's, Nueva York, 28/05/1999, lot. 38), Lodewijk de Vadder (artista flamenco autor de un dibujo de entre 1620 y 1655 conservado en la Bibliothèque Royale de Belgique, Brussel, inv. F 16027), Herman Saftleven (artista de Rotterdam autor de un dibujo de entre 1624 y 1685, conservado en la Graphische Sammlung del Städelschen Kunstinstitut, en Frankfurt, inv. 936), Alexander Keirincx (artista de Amberes autor del óleo sobre tabla de una Vista del Norte (Inglaterra) con dibujante a la izquierda de 1639, vendida en el Dorotheum, Viena, el 21/04/2010, lot. 113), Jacob Esselens (artista de Amsterdam que firma un dibujo de entre 1641 y 1687 conservado en el Teylers Museum de Haarlem, inv. Q 59), Lambert Doomer (artista de Amsterdam relacionado con Rembrandt autor de una aguada de 1646 de 43,2 x 60 cm, conservada en Nantes, en el Musée Départemental Dobrée, inv. 56-52-48, y otro dibujo del mismo tema de ca. 1670 de $23,7 \times 41,6 \mathrm{~cm}$ comentado en Jeanine Otten \& Cornelis Schepel: Getekende stads-en dorpsgezichten uit de Topografische Atlas Gelderland. Veluwezoom, Nijmegen en omgeving, Rivierengebied, Westervoort, Van Gruting, 2000, nr. 034), y Jan Looten (artista ho- landés autor de un Paisaje de montaña con dibujante de entre 1649-1681, en óleo sobre tela, $52,1 \times 67 \mathrm{~cm}$, vendido en Sotheby's, Amsterdam, 05/11/2002, lot. 107). En la serie Plaisante Lantschappen del citado Visscher participaron también Roelant y Geertruyd Roghman; del primero se conserva un dibujo de paisaje rocoso con dibujante de $18,7 \times 25,3 \mathrm{~cm}$ (realizado entre 16351686 , vendido en Sotheby's, Londres, 04/07/2007, lot 180). Por fin, Jacques d'Arthois, un artista de Bruselas especializado en paisaje en cuyos cuadros las figuras solían ser realizadas por artistas como David Teniers el Joven) firma dos óleos sobre tabla con artista en paisaje de entre 1628 y 1686: uno de $45 \times 61 \mathrm{~cm}$, vendido en Servarts, Bruselas, 20/11/2001, lot. 249; y otro de $33,7 \times 45,4 \mathrm{~cm}$ vendido en Christie's, Londres, 04/07/1997, lot. 38. A esta lista cabe añadir, algún anónimo (por ejemplo, el autor de un óleo sobre tabla del círculo de Koninck de una marina con dibujantes de $37,5 \times 51,4 \mathrm{~cm}$ de hacia 1640-1650, vendido en Christie's, Londres, 12/12/2003, lot. 25). El archivo digital del Rijksmuseum, nos permite incluir el nombre de Abraham Furnerius (un discípulo de Rembrandt que no parece haber visitado Italia) y que firma un apunte a tinta y aguada sobre papel titulado Houten huis en tekenaar [Casa de madera y dibujante] entre 1638 y 1654, 15,6 x 20,6 cm, conservado en el Rijksmuseum, inv. RPT-1884-A-305, muy parecido al citado de Bloemaert. Además, a los dibujos de personajes sentados de espaldas de las aguadas de Lambert Doomer, que sí incluye el RKD, la base de datos del Rijksmuseum añade el dibujo: Gezicht op Hoch-Elten met een tekenaar [Vista en Hoch-Elten con un dibujante], 1663, lápiz sobre papel, $21,6 \times 35$ cm, inv. RPT-1919-45.

17 Piénsese que, de todos los artistas que no viajan a Italia y que lo preceden en los Países Bajos del XVII, pocos o muy pocos son capaces de introducir el tema del paisajista en el paisaje en un óleo. La mayoría lo introducen en bocetos, y algunos en grabados. Sólo cuatro de los citados en la nota anterior son autores de verdaderos cuadros, a saber, el extraordinario Esaias van de Velde, Alexander Keirincx, Jan Looten y Jacques d'Arthois. Pero, entre ellos, es muy probable que Looten y d'Arthois firmasen sus obras después de 1650 .
Sobre el cuadro de Esaias van de Velde, véase, George S. Keyes \& J. G. C. A. Briels: Esaias van de Velde, 1586-1630, Doornspijk [Holanda], Davaco, 1984, nr. 132; y sobre el de Keirincx, R. P. Townsend: "Alexander Keirincx's royal commission of 1639-1640» en Juliette Roding, Eric Jan Sluijter, Bart Westerweel, Marijke van der Meij-Tolsma, Eric Domela Nieuwenhuis (eds.): Dutch and Flemish artists in Britain 15501800, Leiden, Primavera, 2003, págs. 137-150.

${ }^{18} \mathrm{~V}$. W. Stechow: «The Italian Scene» en Op. cit., 1966, págs. 147-166.

19 V. Didier Bodart: «Paul Bril et les paysagistes flamands a Rome avant 1630» en Les peintres des PaysBas méridionaux et de la principauté de Liège à Rome au XVIleme siècle, Bruxelles-Rome, Institut Historique Belge de Rome, 1970, I, págs. 212 y ss.; y Francesca Cappelletti: Paul Bril e la pittura di paesaggio a Roma, 1580-1630, Roma, Ugo Bozzi, 2006

${ }^{20}$ Tinta sobre papel, $27,2 \times 41,3 \mathrm{~cm}$, y catalogado por Michael Jaffé en The Devonshire Collection of Northern European Drawings, Turin, Umberto Allemandi \& C. 2002, tomo 2, nr. 1205. Aparece con la inscripción «Bril», por eso Schatborn, 2001, pág. 38, afirma que no conservamos obras conocidas suyas. Por otro lado, Nieulandt I ya era citado en la edición francesa del Schilderboek de Mander de Henry Hymans -Paris, 1885, tomo II, pág. 248- como autor de «une grande estampe en trois feuilles, du Tibre et de l'ile Tiberine, où le peintre est vu dessinant dans une barque». Pero no he logrado localizar esta otra obra.

${ }^{21}$ Tinta y aguada sobre papel, 26 $x$ 18,3 cm, Amsterdam, Rijksmuseum, inv. RP-T-1898-A-3557.

22 El primero, de $26,1 \times 37 \mathrm{~cm}$, se conserva en Munich, en la Staatliche Graphische Sammlung, inv. 1987:15; el segundo, una tinta sobre papel, de $27,5 \times 42,2 \mathrm{~cm}$, forma parte de una colección particular (v. M. Jaffé, The Devonshire Collection, Op. cit., 2002, tomo 2, nr. 1302).

${ }^{23}$ Tinta sobre papel, 17,8 x 15,3 $\mathrm{cm}$; Stiftung Weimarer Klassik und Kunstsammlungen, inv. 4587.

${ }^{24}$ Es de de $20,3 \times 29,8 \mathrm{~cm}$, se conserva en el Goethe Nationalmuseum, Weimar, inv. 811. Al respecto, v. 
RKD. Durante mucho tiempo se consideró que este dibujo se debía a la mano de Paul Brill.

${ }^{25}$ Los que sí destacan el papel de Van Laer entre los paisajistas italianizantes de la primera generación son Jakob Rosenberg y Seymour Slive en "Los pintores italianizantes» en Arte $y$ arquitectura en Holanda, 1600-1800, Op. cit., 1994, págs. 301-318, especialmente, págs. 307-310. Para este tema, véanse también los textos del catálogo Laurie B. Harwood; Christopher Brown; Anne Charlotte Steland: Inspired by Italy: Dutch Landscape Painting 1600-1700, London, Dulwich Picture Gallery, 2002.

${ }^{26}$ V. Godefridus Johannes Hoogewerff: De Bentvueghels, La Haya, Martinus Nijhoff, 1952.

${ }_{27}$ Pintado después de 1614 y antes 1642 , de $70,9 \times 132,6 \mathrm{~cm}$, y subastado en Sotheby's, Londres, 04/12/2008, lot. 208.

${ }^{28}$ De Swanevelt es un dibujo a lápiz sobre papel titulado: Landschap met ruïne en tekenaar, realizado entre 1629-1641, años en los que permanece en Roma; 18,2 x 28,3 cm, Rijksmuseum, Amsterdam, inv. RP-T-1928-3. Además, también es de su autoría alguna vista de Campo Vaccino.

29 Bloemaert es el autor de un boceto de dibujante entre casitas rurales de 1595-1605 conservado en el Schlossmuseum de Weimar, inv. 4492.

${ }^{30}$ Se trata de un óleo sobre lienzo, de $115,6 \times 88,7 \mathrm{~cm}$ conservado en el Thyssen-Bornemisza, Madrid. Sugiere la lectura moralista Ivan Gaskell en Seventeenth Century Dutch and Flemish Paintings: The Thyssen-Bornemisza Collection, London, 1990, pág. 443. Al respecto, véase también, P. Sutton: El Siglo de Oro, Op. cit., 1994, pág. 90.

31 V. Joachim von Sandrart: Der Teutsche Academie der Bau-Bild und Mahlerey-Künste [La academia alemana del arte de la arquitectura, la escultura y la pintura], Nürnberg, Imp. Johann-Philipp Miltenberger, 1675, II, libro 3, págs. 311-313, ahora digitalizado en http://ta.sandrart.net [última consulta: 26/11/2011].

32 V. Pierre Rosenberg \& Keith Christiansen: Poussin and Nature. Arcadian Visions, New York, Metropolitan Museum of Art, 2008, pág. 317; y, antes, Pierre Rosenberg \& Louis-Antoine
Prat: Nicolas Poussin, 1594-1665. Catalogue raisonné des dessins, Milano, Leonardo, 1994, tomo II, pág. 1151.

${ }^{33}$ Los dos son óleos sobre lienzo. Del primero, de $65.4 \times 95 \mathrm{~cm}$, conservado en el Spencer Museum of Art, Lawrence, University of Kansas, inv. L1982.002, existe copia en el Metropolitan Museum of Art de Nueva York, inv. 1975.152. El segundo, de 61,6 $x$ 84,5 , se guarda en el Museum of Fine Arts de Boston, inv. 44.72. Sobre ambos, véase: Helen Diane Russell: Claude Lorrain, 1600-1682, Washington, National Gallery of Art, 1982, págs. 76-78, y 121-122; sobre el segundo: Marcel Roethlisberger: Claude Lorrain. The Paintings, 2 vol. New Haven, 1961, cat. nr. 22.

${ }^{34}$ Entre los dibujos de Lorena, que se localizan rápido gracias al pormenorizado catálogo de Marcel Roethlisberger, recordar: (1) Arroyo rocoso con artista sentado, de hacia 1635, es un lápiz de grafito, tiza roja y carboncillo, y tinta marrón, 26,4 x 35,7 cm, del Teyler Museum, Haarlem, inv. L 44; (2) Paisaje con cazadores $y$ artista, $n^{\circ} 24$ del Liber Veritatis, de hacia 1637 se conserva en el British Museum, inv. 1957,1214.30, aunque luego fue impreso en sepia y publicado por John Boydell en 1774; (3) Un artista dibujando con una segunda figura mirando, carboncillo y aguada sobre papel blanco, que perteneció al arquitecto y paisajista Richard Payne Knight, de 21,4 × 32,1 cm, realizado entre 1635 y 1640, guardado en el British Museum, inv. 7.181; (4) Vista con árboles y dibujante, lápiz sobre papel azul, 19,5 x 30,8 cm, que se conserva en el Albertina (Viena), inv. 11.514; y (5) Paisaje fluvial, 27,2 x 41,5 cm, del Instituto Holandés de París, colección Frits Lugt, en el que un personajillo parece estar dibujando a sus compañeros. Sobre todo esto, véase M. Roethlisberger: Claude Lorrain. The Drawings. Catalog, Berkeley \& Los Angeles, University of California Press, 1968, págs. (cat. nr.): 107 (90), 127 (163), 150 (290), 219 (538), y 230 (576), respectivamente. Haciendo balance, Roethlisberger, pág. 150 , señala que los dibujos de paisajes con dibujantes son frecuentes en los primeros años de actividad de Lorena.

${ }^{35}$ Se trata de un óleo sobre lienzo de 78.1 x $101 \mathrm{~cm}$, de 1639 conservado en el Cincinnati Art Museum, inv. 1946.102;. Al respecto, véanse: $M$.
Roethlisberger: Claude Lorrain. The Paintings, Op. cit., 1961, cat. nr. 44. ; H. D. Russell: Op. cit., 1982, cat. nr. 25, págs. 149 y 152. Este óleo se ha asociado a un cuadro de Both que comentaré luego: J. Burke: Jan Both. Op. cit., 1976, págs. 64 y ss., y 167-168. Asimismo, tiene relación con un grabado de Lorena realizado en esa misma época, 1639, del que en el British Museum y en el Art Institute of Chicago se conservan copias y que en inglés recibe el título de Coast Scene with an Artist, ca. 1638-1641, 12,8 x $18 \mathrm{~cm}$ (Russell, 1982, págs. 379-380). Otro grabado de su firma y tema parecido se conserva en la Biblioteca Nacional de París, 10,2 x 16,8 cm, y lo reproduce Russell, 1982, págs. 309-311. Por fin, parece ser que de Lorena se conservan otros cuadros del mismo tema, por ejemplo, un Paisaje con dibujante de $95 \times 122 \mathrm{~cm}$, en el Buckingham Palace de Londres, de que se conocen, al menos, cuatro versiones y que cita M. Roethlisberger en revisión posterior: Claude Lorrain, Paris, Flammarion, 1986, pág. 128.

${ }^{36}$ Marcel Roethlisberger (en Claude Lorrain. The Paintings, New Haven, 1961, tomo 1, págs. 47-51, y en «Nature Drawings» en Claude Lorrain. The Drawings, 1968, págs. 35-44) insiste, apoyándose en diversas fuentes y en las propias inscripciones, en que Claude estaba constantemente tomando apuntes del natural, pero recuerda (1961, 528) que sus figuras fueron pintadas por otros. Sin embargo, más recientemente, Russell ha afirmado que depende de los casos y que muchas parecen ser de su mano, 1982, págs. 77 y 121. Teniendo en cuenta que la mayoría de las obras que incluyen dibujantes en el paisaje fueron realizadas en los años en los que tomó más apuntes del natural (años treinta y cuarenta), y teniendo en cuenta que, justo cuando los pequeños dibujantes fueron desapareciendo de sus cuadros en los cincuenta y sesenta, dejó el francés de tomar apuntes del natural, parece evidente que, con ellos, el artista por excelencia del paisaje ideal apelaba a cierta realidad.

${ }^{37}$ V. J. Burke: Jan Both. Op. cit., 1976, págs. 41 y ss.; Rosenberg \& Slive: Op. cit., 1994, pág. 310.

38 Como indican Hoogewerff y Schatborn, Both y su hermano Andries pertenecían a la «Bandada». V. Hoogewerff: De Bentvueghels, La Haya, 
Martinus Nijhoff, 1952, págs. 89 y 90; Schatborn \& Verberne, 2001, págs. 88-99; también, Stechow, 1968, págs. 154 y ss. Lo que apenas ha sido muy comentado en conjunto es la constante incidencia del grupo en el tema del paisajista en el paisaje.

39 V. Burke: Jan Both. Op. cit., 1976, para Van Laer, págs. 125 y ss., y para la conexión con Lorena, pág. 64.

${ }^{40}$ Jan Asselijn (ca. 1615 - ca. 1652), apodado «Cangrejito» por su mano deforme, fue otro de los Bentvueghels de segunda generación cercanos a Lorena y Both. Sus Bentvueghels' dibujando según modelos naturales, tiza y aguada del Kupferstichkabinett, Staatliche Museen, Berlín, n 1420, es uno de los mejores testimonios que guardamos de esas excursiones colectivas para realizar croquis que, desde su llegada a Roma en 1635 y hasta su marcha en 1644, se acostumbró a frecuentar. En las mismas conoció a Both y a Lorena, de los que aprendería el estilo claro y puro que luego se exportaría a Holanda. Posteriormente, firmaría unas Ruinas (¿del Coliseo?) con dibujantes en primer plano (que forma parte de la colección de la Galería Nacional de Praga, inv. 0-333. Por otro lado, no tenemos pruebas claras de la estancia de Nicolaes (o Claes) Pietersz. Berchem (1620-1683) en Roma, pero algunos estudios hablan de su visita en 1642, y en su Gezicht op de ruïnes van het Colosseum, ca. 1679-1683 (lápiz, pluma y aguada sobre papel, $51,7 \times 62,2 \mathrm{~cm}$, guardado en el Rijksmuseum, inv. RPT-1883-A-277) aúna las vistas arqueológicas con el subgénero del artista en el paisaje que allí estaba de moda. Con Asselijn, Berchem y Both debió moverse Jan Baptist Weenix (1621 - ca. 1660) que firmó dos dibujos, probablemente en los años cuarenta, titulados Artista dibujando cerca de una fortificación y Dos artistas dibujando en una ruina (respectivamente, un carboncillo de 10,2 x 16,5 cm conservado en Bruselas: Koninklijke Musea voor Schone Kunsten, Colección De Grez, y el segundo una aguada en grises de $21,7 \times 26,8$ cm conservada en el Museo Boijmans de Rotterdam). Para los dibujos de artistas en el paisaje de Asselijn, Berchem y Weenix, véase, Schatborn \& Verberne: Drawn to Warmth, Op. cit., 2001, págs. 22, 100-110, 111-113 y 187-195. De ese grupo formarían parte también
Karel Dujardin (1626-1678), que, tras ir a clases de Berchem, llega a Roma en 1643, y Adam Pynacker (1622-1673). Pero a ellos me referiré más adelante.

${ }^{41}$ Los Angeles County Museum of Art, $104,46 \times 118,11 \mathrm{~cm}$, inv. M.2009.106.3. V. J. Burke: Jan Both. Op. cit., 1976, págs. 64 y ss., 167-168, y 238-239, cat. nr. 96; y Peter C. Sutton: Op. cit., 1994, pág. 86, cat. nr. 12.

${ }^{42}$ Me refiero, lógicamente, al gran cuadro que estudio en estas páginas, de 240 x $187 \mathrm{~cm}$, inv. SK-C-109, y cuya bibliografía ya ha sido citada antes.

${ }^{43}$ A pesar de su corta vida, se le considera el "padre» de esta segunda generación; véase, Harwood \& al.: Inspired by Italy, Op. cit., 2002, pág. 25.

${ }^{44}$ V. Sergio Bertelli: Rebeldes, libertinos $y$ ortodoxos en el Barroco, Barcelona, Península, 1984, págs. 216217. También, Schatborn \& Verberne: Drawn to Warmth. Op. cit., 2001, catálogo ya citado en el que se muestra la importancia del viaje a Italia entre los mercaderes, artistas y nobles holandeses de la época.

45 La importancia del tema del viaje en Lorena es subrayada por H. D. Russell en «L'interprétation des oeuvres de Claude Lorrain» en Op. cit., 1982, págs. 91-94. Mientras, el cuadro de Salvator Rosa al que hago referencia es un óleo sobre lienzo, 108,3 x 174,2 $\mathrm{cm}$, de la National Gallery de Londres. Se compara esa obra de Rosa con la de Both en: Jonathan Scott: Salvator Rosa. His Life and Times, New Haven / London, Yale University Press, 1995, pág. 36

46 La pintura se reproduce en Stephen Reiss: Aelbert Cuyp, London, Zwemmer, 1975, pág. 160 (fig. 120). Para el dibujo, véase el catálogo Dessins de paysagistes hollandais du XVIle siècle: de la collection particulière conservée à I'Institut néerlandais de Paris, a cargo de Carlos van Hasselt, Paris / Brussels, Institut Néerlandais de Paris / Bibliothèque Royale de Belgique, 196869, págs. 34-35 (n. 32, fig. 103).

${ }^{47}$ Dicha transformación comenzaría a mediados de los años cuarenta del siglo XVII. V. Stechow, Op. cit., 1968, pág. 62; Reiss, Op. cit., 1975, págs. 8-9 y 71.

${ }^{48}$ W. Stechow (Op. cit., 1968, pág. 40) incide en la importancia de Aelbert
Cuyp como artífice de vistas con dibujantes. Cuyp fue un conocido paisajista holandés que, sin bajar a Italia, emuló a Jan Both, por lo que sus paisajistas en el paisaje deben proceder de la imitación del tema en este. Se conservan más obras de Cuyp o de seguidores de Cuyp que introducen al dibujante en el paisaje, v. gr., Torre Merwede con artista dibujando, reproducida en Reiss: Op. cit., 1975, pág. 105 (fig. 70).

${ }^{49}$ V. Schatborn \& Verberne: «Andries Both \& Jan Both» en Drawn to Warmth, Op. cit., 2001, págs. 88-99.

50 Ya Stechow dudaba de que Jan Both recibiese ayuda: Op. cit., 1968, pág. 7; y descarta también que Andries jugase ese papel de especialista en figuras para su hermano Jan, Malcolm R. Waddingham en "Andries and Jan Both in France and Italy» en Paragone 15, n 171, 1964, págs. 13-43.

$51 \mathrm{El}$ de la Staatliche Graphische Sammlung de Munich (que reproducen Schatborn \& Verberne: Op. cit., 2001, pág. 95) es el lápiz y aguada sobre papel, de $18,7 \times 29 \mathrm{~cm}$, con puente y sin personajes. El del Museo Nacional de Suecia, Estocolmo, inv. NMH 127/1866, el lápiz, tinta marrón y aguada sobre papel, de $20,6 \times 32,2 \mathrm{~cm}$, cercano al anterior con un gran camino a la derecha. El de la National Gallery de Irlanda en Dublín, inv. NGI.2020, un dibujo a sanguina de $18,4 \times 26,4 \mathrm{~cm}$, con puente y con personajes. $Y$ el del British Museum, inv. 1895,0915.1126, la pequeña obra maestra de 39,3 x $30,8 \mathrm{~cm}$, de sorprendente parecido con el gran óleo de Amsterdam.

52 V. Schatborn \& Verberne: Op. cit., 2001, págs. 88-99.

53 Salvando las distancias, en el anterior párrafo parafraseo al Roland Barthes de "La muerte del autor» en El susurro del lenguaje. Más allá de la palabra y la escritura, Barcelona, Paidós, 2009, págs. 75 y ss. Pero, donde él hablaba de Balzac, yo me refiero al paisaje realista holandés del XVII.

${ }^{54} \mathrm{~V}$. Anthony Blunt: «Poussin studies VIII -a series of Anchorite subjects commissioned by Philip IV from Poussin, Claude and others» en Burlington Magazine, London, vol. 101, $\mathrm{n}^{\circ} 680$, nov., 1959, pp. 387-390. Y, recientemente, Giovanna Capitelli: «Los paisajes para el Palacio del Buen Retiro» en El Palacio del Rey Planeta. Felipe IV y 
el Buen Retiro [catálogo de exposición], Madrid, Museo del Prado, 2005, páginas 241-284.

55 Óleo sobre lienzo de 61,6 x 84,5, del Museum of Fine Arts de Boston, inv. 44.72. V. M. Roethlisberger: Claude Lorrain. The Paintings, 2 vol. New Haven, 1961, cat. nr. 22; H. D. Russell: Claude Lorrain, 1600-1682, Washington, National Gallery of Art, 1982, pág. 17 y cat. nr. 6 (resume la polémica sobre la datación de la obra de Lorena). Sobre la conexión entre este cuadro de Lorena y la obra de Jan Both, véanse: W. Stechow, Op. cit., 1968, págs. 154-155, y J. Burke: Jan Both. Op. cit., 1976, págs. 64 y ss., y pág. 180.

56 V. J. Burke, 1976, págs. 64 y 180, sí lo comenta; pero Stechow, 1968, págs. 154-15, no.

57 Sobre este cuadro de Lorena se ha planteado que, quizás, las figuras, de estilo bamboccesque, no sean de su mano, y que en estos años se codeaba con Van Laer. En todo caso, sus apuntes sobre el tema muestran que el propio Claudio convirtió el personaje del dibujante en motivo común de sus paisajes. V. H. D. Russell, 1982, pág. 121, se pregunta si la figura del artista es un autorretrato. Para los de Valckenborch remito a Federico L. Silvestre: «El pintor como narrador. Génesis flamenca del paisajismo intradiegético» en Historia, Imagen, Lenguaje, Op. cit., 2012.

${ }^{58}$ El vínculo de las maravillas de la Creación como testimonio del poder del Creador aparece, por ejemplo, en la Institution de la religion chrétienne en el tomo I, cap. XVI, párrafo 2 (eds. Baum, Cunitz \& Reuss; incluida en loannis Calvini opera quae supersunt omnia, Brunsvigae, Schwetsche et Filium, 1865, vol. III, págs. 236-237). Sobre la pintura de paisaje, Calvino dijo, exactamente, lo siguiente: "En cuanto a lo que es lícito pintar o grabar, están, o las historias para recordar, o las figuras o medallas de animales, ciudades o campiñas. Las historias pueden aprovecharse como advertencias o recuerdos que se consideren; en cuanto al resto, no tendrán más sentido que el de dar placer» (Institution de la religion chrétienne, tomo I, cap. XI, párrafo 12 en loannis Calvini opera. Op. cit., 1865, vol. III, pág. 136).

${ }^{59}$ La lectura más abiertamente calvinista del paisajismo holandés del XVII se debe al trabajo de Maarten de Klei- jn: De invloed van het Calvinisme op de Noord-Nederlandse landschapschilderkunst, 1570-1630, [La influencia del Calvinismo en la pintura de paisaje de los Países Bajos del Norte], Apeldoorn, Willem de Zwijgerstichting, 1982, que ha tenido el valor de poner en cuestión la secular asociación de cultura profana y emergencia del nuevo paisajismo en la Holanda (en Haarlem) de comienzos del XVII. Sin duda, la concepción esteticista y exclusivamente formalista del arte no era posible en esta época; en todo caso, que la cultura holandesa del XVII todavía fuese religiosa y que su noción del arte fuese distinta a la nuestra, no quiere decir que la nueva relación de calvinismo y paisaje por él propuesta resulte acertada.

${ }^{60}$ Reúne esta pequeña lista Walter G. Gibson en Pleasant places. The rustic landscape from Bruegel to Ruisdael, Los Angeles, University of California Press, 2000, pág. 63.

${ }^{61}$ Esto lo explica bien Reindert L. Falkenburg: "Calvinism and the Emergence of Dutch Seventeenth-Century Landscape Art - A Critical Evaluation» en Paul Corby Finney (ed.): Seeing beyond the word: visual arts and the Calvinist tradition, Michigan, Eerdsman., 1999, pág. 343 y ss.

62 Para confirmar esa raíz común véase el clásico de Ernst Curtius: «E Libro de la Naturaleza» en Literatura europea y Edad Media latina, México, FCE, 1955, págs. 448-457.

63 Relaciona catolicismo moderno y paisaje Alain Mérot en «Paysage chrétien et sentiment moderne de la nature» en Du paysage en peinture dans I'Occident moderne, Gallimard, 2009, págs. 217-251, especialmente, para Both, pág. 228.

${ }^{64}$ Piénsese, en primer lugar, que, cuando se trata de las obras pintadas por Both junto a Lorena, Poussin, Dughet, Van Swanevelt, Miel o Lemaire, para Felipe IV, estamos obligados a hablar de cierta visión católica del mundo, pues algunos encargos hacían referencia a vidas de Santos (sobre el encargo de Felipe IV a Both, Poussin..., en Roma, v. Anthony Blunt: "Poussin studies VIII ...» en Burlington Magazine, Art. cit., 1959, págs. 387-390; y G. Capitelli: Op. cit., 2005, págs. 241-284). Del mismo modo, cuando pensamos en las obras realizadas a su regreso a Holanda, parecería más correcto aplicar una lectura protestante. Pero el estudio de los inventarios de Delft llevado a cabo por John Michael Montias (Artist and Artisans in Delft, Princeton, Princeton University Press, 1982) mostró hace años que, al menos desde 1650 a 1679 - es decir, cuando entra en escena la obra de Jan Both analizada-, los hogares católicos se acercaban con el mismo interés que los protestantes al género del paisaje.

65 Sobre esto, véase Federico López Silvestre: «Dios y la naturaleza. El desarrollo de la Teología natural en España y en Galicia en el siglo XVIII» en Semata, 2003, 14, págs. 417-453.

${ }_{66}^{6}$ Para el tema de los caminos y los viajeros como motivo simbólico de los paisajes de los Países Bajos del siglo XVI y principios del XVII, véanse: Reindert L. Falkenburg: Joachim Patinir: Landscape as an Image of the Pilgrimage of Life, Amsterdam / Philadelphia, John Benjamins, 1988, págs. 81-82; HansJoachim Raupp: "Thema und Bedeutung» en Landschaften und Seestücke, Op. cit., 2001, págs. 24-28, y Leopoldine Prosperetti: Landscape and Philosophy in the Art of Jan Brueghel the Elder (1568-1625), Surrey, Ashgate, 2009, págs. 4-9.

${ }^{67}$ V. Burke: Jan Both. Op. cit., 1976, págs. 41 y ss.; Rosenberg \& Slive: Op. cit., 1994, pág. 310.

${ }^{68}$ Fechado hacia 1625 , se conserva una copia de este grabado de Cornelis Bloemaert basado en un dibujo de Abraham Bloemaert, en el British Museum, inv. D,7.204. 10,8 x 15,5 cm Se trata de uno de un conjunto de dieciséis. Al respecto, M. Roethlisberger: Abraham Bloemaert and his sons: Paintings and prints, 2 vols, Ghent, 1993, 303.

${ }^{69}$ Esta lectura moderna lúdica y sensualista se sugiere en F. Nietzsche, y se hace explícita en E. Gombrich, S Alpers y W. Gibson. Walter G. Gibson lanza su crítica contra la lectura moralista y religiosa en Pleasant places. The rustic landscape from Bruegel to Ruisdael, Los Angeles, University of California Press, 2000, págs. XXVII y 117-118. De esta obra, pág. XVIII, extraigo la cita entre comillas. En la pág. 117, Gibson comenta el concepto de staffage -expresión técnica ya citada, manejada entre historiadores del arte ingleses y alemanes, para hablar de los personajillos que se pintan en los paisajes- para 
mostrar que, etimológicamente, ese término procede del alemán stafiren o staffieren y sólo significa «decorar, adornar, embellecer».

${ }^{70}$ V. Anthony Blunt: Nicolas Poussin, London, Pallas Athene, 1995, págs. 157 y ss.

71 V. W. Stechow: Op. cit., 1966, págs. 156-161; James D. Burke, Jan Both, Op. cit., 1976, pág. 18; y Laurie B. Harwood: Adam Pynacker, c. 16201673, Doornspijk, Davaco, 1988, págs. $27,40-48$ y $62-64$. Por otro lado, nativo de Amsterdam, discípulo de Berchem, y directamente relacionado con Both, Karel Dujardin (1626-1678) se diferencia de los anteriores en que realizó sus viajes a Italia a partir de 1650 -uno antes de agosto de 1650 (momento en el que se encuentra en Lyon, quizás regresando del Sur) y otro en agosto de 1675 (se sabe que está en Roma ese año, y en 1676 y 1678)-. Sin embargo, en su Paisaje con artista dibujando ruinas de 1651 mantuvo viva la misma tradición iconográfica que estamos historiando (v. Jennifer Kilian: The paintings of Karel Du Jardin, 1626-1678, [catálogo de exposición], Ed. John Benjamins, 2005, págs. 79 y 329; y, sobre la relación de Dujardin con el grupo holandés en Roma, Hoogewerff, Op. cit., 1952, pág. 93). En este grupo de rezagados cabe incluir también a Pieter Moninckx, que a pesar de ser más viejo -pues había nacido hacia 1606- estuvo en Italia entre 1656-1672, firmando sólo entonces sus paisajes con dibujantes (v. Schatborn \& Verberne: Drawn to warmth: Op. cit., 2001, págs. 162-3).

72 Publicado originalmente en Arnold Houbracken, De groote schouburgh der Nederlantsche konstschilders en schilderessen, Amsterdam, 171821, vol. 2, págs. 97-99, y traducido al inglés por Walter S. Gibson: «Painting for Pleasure» en Op. cit., 2000, págs. 67-68, lo que he leído en ese idioma dice así: "Here can Heer Backer, when the trees are devoid of leaves / And the barren field is overwhelmed with dunes / Of Drifting snow, contemplate these leafy crowns, / The green of foliage, a Summer for the eye. / Here, worn out by cares of state, he can unstring / His bow, revelling in their contemplation».

73 V. Laurie B. Harwood: Adam Pynacker, Op. cit., 1988, págs. 168169, donde cita el cuadro de Both del Rijksmuseum al hablar de las Ruinas en un paisaje boscoso de Pynacker, $35 \times 27$ $\mathrm{cm}$, que incluye un dibujante en primer plano. En otro lugar, Fig. 32, Harwood reproduce también el Paisaje con dibujante de Jan Both de Los Angeles.

${ }^{74}$ Me refiero a la gran tabla de Pynacker del Museo Boijmans pintada entre 1665-1670, $297 \times 270 \mathrm{~cm}$, inv. 1685.

5 V. Arthur Schopenhauer: El mundo como voluntad y representación, tomo I, Madrid, FCE, 2003, § 34, págs. 268-269.

76 V. Joachim Ritter: «Paisaje. Reflexiones sobre la función de lo estético en la sociedad moderna» en Subjetividad. Seis ensayos, Barcelona, Alfa, 1986, págs. 125-158.

77 Que, asociada sin duda a esta imagen de la paz, la moda del «artista en el paisaje» se seguirá extendiendo posteriormente en los Países Bajos, lo ponen de manifiesto numerosas obras. Recordemos, para terminar, los nombres de algunos pintores que seguirán utilizando el motivo entre 1650 y 1700 (para elaborar esta última lista he utilizado, sobre todo, los archivos digitales del Instituto Holandés de Historia del Arte [Rijksbureau voor Kunsthistorische Documentatie] y del Rijksmuseum de Amsterdam):

1) Entre los que la aplican sin salir de los parámetros genuinamente holandeses después de 1650 y antes de 1690 destacan: Jan de Bisschop o Jan Episcopius (1628-1671, artista de Amsterdam que puede relacionarse con el taller de Breenbergh pero que firma un dibujo de $24,5 \times 48,2 \mathrm{~cm}$, de entre 1650 y 1671 conservado en la Graphische Sammlung del Albertina, en Viena, inv. 10112, y otro de 12,1 x $21 \mathrm{~cm}$ de, entre 1643 y 1671 , conservado en una colección particular, y comentado en Jaffé: The Devonshire Collection of Northern European Drawings, Turín, 2002, tomo 3, pág. 369 , que por su tendencia a la horizontalidad encajan mejor con el arte de Haarlem), Jacob van Ruisdael (ca. 1628 - 1682, con una pintura titulada Gezicht op de duinen bij Bloemendaal met op de voorgrond een ruïne de ca. 1665-1670, 53,3 x 60,6 cm, conservada en colección particular suiza desde 1999), Gerrit Adriaensz. Berckheyde (1638-1698, pintor de Haarlem del estilo de Pieter Saenredam que realiza un cuadro de este tema, Het landgo- ed Elswout bij Overveen, $52 \times 80 \mathrm{~cm}$, entre 1653 y 1698 sin ir nunca a Italia, que se conserva en el Museo Frans Hals de Haarlem, inv. 464 b), Nicolaes Maes (1634-1693, artista de Dordrecht discípulo de Rembrandt, que realiza un dibujo con dibujante en el paisaje de 1652-53, 10,6 x 15,7 cm, vendido en Sotheby's, Nueva York, 25/01/2002), y Ludolf Bakhuizen (1649-1707, con un paisaje con dibujante pintado de 1689 , $95,5 \times 129,3 \mathrm{~cm}$, vendido en Sotheby's, Londres, 10/04/2003).

2) Por otro lado, mediado el siglo, la escuela de paisajismo italianizante en Holanda se consolida con Willem de Heusch (1640-1692), discípulo de Both en Utrecht, que firma otro Italiaans landschap met tekenaar (1660-1692, $42 \times 58 \mathrm{~cm}$, óleo sobre tabla, Rijksmuseum, inv. SK-A-2324) y un Zuidelijk landschap met ruiter, tekenaar en een veedrijver bij een oversteekplaats van een rivier $(30,5 \times 41,3 \mathrm{~cm}$, ca. $1660-$ 1692, subastado en Londres: Phillips, Son \& Neale, he13/12/1999, lot 51). Entre los que, sin salir del país, emulan el modelo italiano de los Bentvueghels, también figura Adriaen Hendriksz. Verboom (ca. 1628- ca. 1670) que pintará otro Berglandschap met tekenaar [Paisaje boscoso con dibujante] (óleo sobre lienzo, 72 x $64 \mathrm{~cm}$, de entre $1650 \mathrm{y}$ 1670, conservado en el Stedelijk Museum De Lakenhal, de Leiden, que parece remitir a Both. También, encajan en esta escuela Jan Blom (artista de Amsterdam que nunca fue a Italia pero se especializó en paisajes italianos, pintando un Parklandschap mert wandelaars en een tekenende kunstenaar, sobre lienzo de $73,7 \times 88,9 \mathrm{~cm}$ de entre 1650 y 1685 , vendido en Christie's, Nueva York, 04/06/2009).

3) Por fin, con un estilo topográfico distinto, mezcla de lo holandés y lo italianizante, despuntarán rematando el siglo las figuras de Van Wittel, Genoels y Van Lint gracias a sus estancias en Italia. Caspar van Wittel (1653-1736) con El Coliseo y el Arco de Constantino con dibujantes, óleo sobre lienzo, 47 x $107 \mathrm{~cm}$ (v. Giuliano Briganti, Laura Laureati, Ludovica Trezzani: Gaspar Van Wittel, L'Opera Completa, Milano, Electa, 1996, pág. 153, cat. nr. 55), pintado después de su llegada a Italia hacia 1675 , donde permanecería hasta el final de sus días. Por otro lado, Abraham Genoels II (1640-1723), artista flamenco que permanecerá en Roma 
entre 1674 y 1682 , confirmando la misma obsesión. De él es un dibujo de tema arcádico con dibujante (pertenece a la Stiftung Weimarer Klassik und Kunstsammlungen, Weimar, inv. KK 5027) (publicado en Rembrandt und seine Zeitgenossen, Kunstsammlungen zu Weimar (Schloßmuseum), Weimar (Thüringen), 1981, nr. 225 recto). Luego llegará el también flamenco Hendrik Frans van Lint (1684-1763) que, ya más tarde, se incorpora al grupo de los Bentvueghels y permanece en Roma desde 1696 a 1763 . Pinta otra
Vista de Roma y además una Vista del Foro en esos mismos años (medidas: 44 x $71 \mathrm{~cm}$, y $34,9 \times 58,4 \mathrm{~cm}$ ); v. Andrea Busiri Vici: Peter, Hendrik e Giacomo Van Lint. Tre pittori di Anversa del'600 e '700 lavorano a Roma, Roma, Bozzi, 1987). 